\author{
B. Hauer ${ }^{1}$ (federführend), \\ R. Loddenkemper ${ }^{1}$ (federführend), \\ unter Mitarbeit von \\ (in alphabetischer Reihenfolge): \\ A. Detjen ${ }^{2}$, M. Forßbohm ${ }^{3}$, W. Haas ${ }^{4}$, \\ G. Loytved ${ }^{5}$, K. Magdorf' ${ }^{2}$ H. Mauch ${ }^{6}$, \\ A. Nienhaus ${ }^{7}$, H. L. Rieder $^{8}$, \\ D. Sagebiel ${ }^{1}$, T. Schaberg ${ }^{9}$
}

\section{Interferon- $\boldsymbol{\gamma}$-Tests in der Tuberkulose-Diagnostik - Aktueller Stand}

Interferon- $\gamma$ Assays - Description and Assessment of a New Tool in the Diagnosis of Tuberculosis

\section{Zusammenfassung}

Zur Diagnostik der latenten tuberkulösen Infektion (LTBI) stand bislang lediglich der Tuberkulinhauttest (THT) zur Verfügung. Dieses Verfahren weist jedoch weder eine 100\%ige Sensitivität, noch - und dies insbesondere aufgrund seiner Kreuzreaktogenität mit BCG und Umweltmykobakterien - eine 100\%ige Spezifität auf. Der Wunsch nach einem zuverlässigen in vitro-Test wird derzeit besonders in Deutschland noch dadurch verstärkt, dass aufgrund der vollständigen Umstellung von Stempeltest auf Tuberkulintestung nach Mendel-Mantoux und durch die Produktionseinstellung des bisher in Deutschland verwendeten Tuberkulins große Verunsicherung herrscht. Hersteller immunologischer Testverfahren, wie des QuantiFERON ${ }^{\circledR}$ _TB Gold In-Tube (ELISAVerfahren) und des T SPOT-TB-Tests (ELISPOT-Verfahren), welche auf der Interferon- $\gamma$ (IFN- $\gamma$ )-Produktion sensibilisierter T-Lymphozyten basieren, bieten ihre Produkte als mögliche Alternative an. Dieser Beitrag vermittelt einen Überblick über die Funktionsweise der IFN- $\gamma$-Tests, die aktuelle Datenlage sowie die noch unbeantworteten wissenschaftlichen Fragestellungen, mögliche Anwendungsbereiche und Anforderungen an zukünftige klinische Studien. Obgleich die neuen Testverfahren das Potenzial haben, sich langfristig als hilfreiches zusätzliches diagnostisches

\section{Abstract}

Up to now the diagnosis of latent tuberculosis infection (LTBI) was based solely on the tuberculin skin test. However, this method offers neither $100 \%$ sensitivity nor - and this is in particular due to its cross-reactivity with BCG and environmental mycobacteria - a $100 \%$ specificity. The demand in Germany for a more reliable in vitro test is currently enhanced by the change from the multipuncture test to the intradermal (Mendel-Mantoux) test and by the uncertainty resulting from the ceased production of the tuberculin previously used in Germany. The manufacturers of immunologic test methods such as the QuantiFERON $^{\circledR}$-TB Gold In-Tube (ELISA assay) and the T SPOT-TB Test (ELISPOT assay), which are based on the Interferon- $\gamma$ (IFN- $\gamma$ ) production of sensitized T lymphocytes, offer their products as possible alternatives. This article explains the function of the IFN- $\gamma$ tests and gives an overview of the most recent data, possible indications and the open scientific questions to be investigated by future clinical studies. Although the new test methods have the potential to eventually prevail as an additional helpful diagnostic tool, the authors consider a complete replacement of the tuberculin skin test as premature. The IFN- $\gamma$ tests may, however, prove already now to be a useful additional diagnostic method.

${ }^{6}$ Institut für Mikrobiologie, Immunologie und Laboratoriumsmedizin, HELIOS Klinikum Emil von Behring Lungenklinik Heckeshorn, Berlin

${ }^{7}$ Berufsgenossenschaft für Gesundheitsdienst und Wohlfahrtspflege, Hamburg ${ }^{8}$ Kirchlindach/Schweiz

${ }^{9}$ Zentrum für Pneumologie, Diakoniekrankenhaus Rotenburg 
Mittel anzubieten, ist ein kompletter Ersatz des Tuberkulinhauttests nach Einschätzung der Autoren verfrüht. Als ergänzende diagnostische Verfahren könnten sich die IFN- $\gamma$-Tests jedoch bereits jetzt durchaus als nützlich erweisen.

\section{Hintergrund}

Die Weltgesundheitsorganisation (WHO) schätzt, dass ein Drittel der Weltbevölkerung mit Mycobacterium (M.) tuberculosis infiziert ist. Aus diesem „Pool“ werden immer neue behandlungsbedürftige Tuberkulosen generiert, da etwa $5-20 \%$ der Infizierten im Laufe ihres Lebens an Tuberkulose (TB) erkranken [1,2]. HIV-Infektion und Immunsuppression anderer Ursache, sowie unter anderem bestimmte Malignome und Unterernährung, erhöhen das Risiko eines Übergangs in eine aktive Erkrankung erheblich $[3,4]$. Die Entwicklung einer behandlungsbedürftigen Tuberkulose lässt sich mittels einer präventiven Chemotherapie deutlich reduzieren. Das Vorgehen der Wahl - Sensibilität des Erregers vorausgesetzt - ist die Gabe von Isoniazid (INH) über neun Monate [3,4]. Die frühzeitige Erkennung und effiziente Therapie einer latenten tuberkulösen Infektion (LTBI) gewinnt, insbesondere in Niedrigprävalenzländern, eine zunehmende Bedeutung.

Zur Diagnostik der LTBI stand bisher lediglich der Tuberkulinhauttest (THT) zur Verfügung. In Deutschland wurde dieser bislang mit gereinigtem Tuberkulin der Firma Chiron Vaccines Behring (GT 10) nach Mendel-Mantoux durchgeführt. Viele Jahre lang kam auch das Stempeltestverfahren zum Einsatz, welches jedoch aufgrund der mangelnden Standardisierbarkeit in Sensitivität und Spezifität der Methode nach Mendel-Mantoux unterlegen ist $[5,6]$. Der zuletzt in Deutschland erhältliche Stempeltest ist seit 2004 nicht mehr verfügbar und die Umstellung auf die Testung nach Mendel-Mantoux hat bei vielen Ärzten und Ärztinnen zu großer Verunsicherung geführt. Nachdem Chiron Vaccines Behring vergangenes Jahr kurzfristig und überraschend auch die Produktion von GT Behring Tuberkulin eingestellt hatte, war, bis zur Zulassung eines alternativen Produkts in Deutschland, der Import anderer Tuberkuline aus dem Ausland notwendig [7]. Seit August 2005 ist in Deutschland das von der Weltgesundheitsorganisation (WHO) als Referenztuberkulin empfohlene dänische Tuberkulin PPD RT 23 des Statens Serum Instituts zugelassen (www.ssi.dk). Weitere Informationen zum PPD RT 23 sind auf der homepage des Paul-Ehrlich-Institutes abrufbar (www.pei.de).

Der Tuberkulinhauttest basiert auf einer spezifischen lymphozytären Immunantwort vom Typ der verzögerten Hypersensitivität auf iatrogen zugeführte Proteine (PPD = purified protein derivative) (Abb.1). PPD stellt dabei eine Mischung aus über 200 verschiedenen Antigenen dar, welche nicht nur bei M. tuberculosis, sondern auch bei M. bovis BCG und verschiedenen Umweltmykobakterien (Synonyme: nicht-tuberkulöse oder atypische oder ubiquitäre Mykobakterien) vorhanden sind [8,9]. Eine frühere BCG-Impfung oder die Kreuzreaktion bei Exposition zu Umweltmykobakterien sind daher mögliche Ursachen für falsch-positive Reaktionen. Zu falsch-negativen Testresultaten kann es hingegen unter anderem bei immunsupprimierten Patienten kommen (z.B. schwere TB-Verlaufsformen, fortgeschrittene HIV-Infektion, Einnahme von Immunsuppressiva, bei bestimmten Virusinfektionen, sehr hohem Lebensalter). Aufgrund der nicht optimalen Sensitivität und Spezifität des THT sind die positiven und negativen prädiktiven Werte nur bei ausreichend hoher Infektionsprävalenz in der untersuchten Personengruppe zufriedenstellend [6]. Die Anlage, Ablesung und Interpretation des Tests sind mögliche Fehlerquellen und erfordern zudem Erfahrung [10]. Darüber hinaus stellt die Notwendigkeit, dass der Untersuchte erneut zum Ablesen des Tests erscheinen muss, im praktischen Alltag häufig ein Problem dar. Aus diesen Gründen ist der Tuberkulinhauttest kein optimales diagnostisches Mittel zur Detektion einer LTBI, zuverlässigere Methoden werden dringend benötigt.

Bei Personen, welche mit M. tuberculosis-Komplex infiziert sind, finden sich im Blut sensibilisierte Lymphozyten, welche spezielle mykobakterielle Antigene erkennen und infolge davon im Sinne

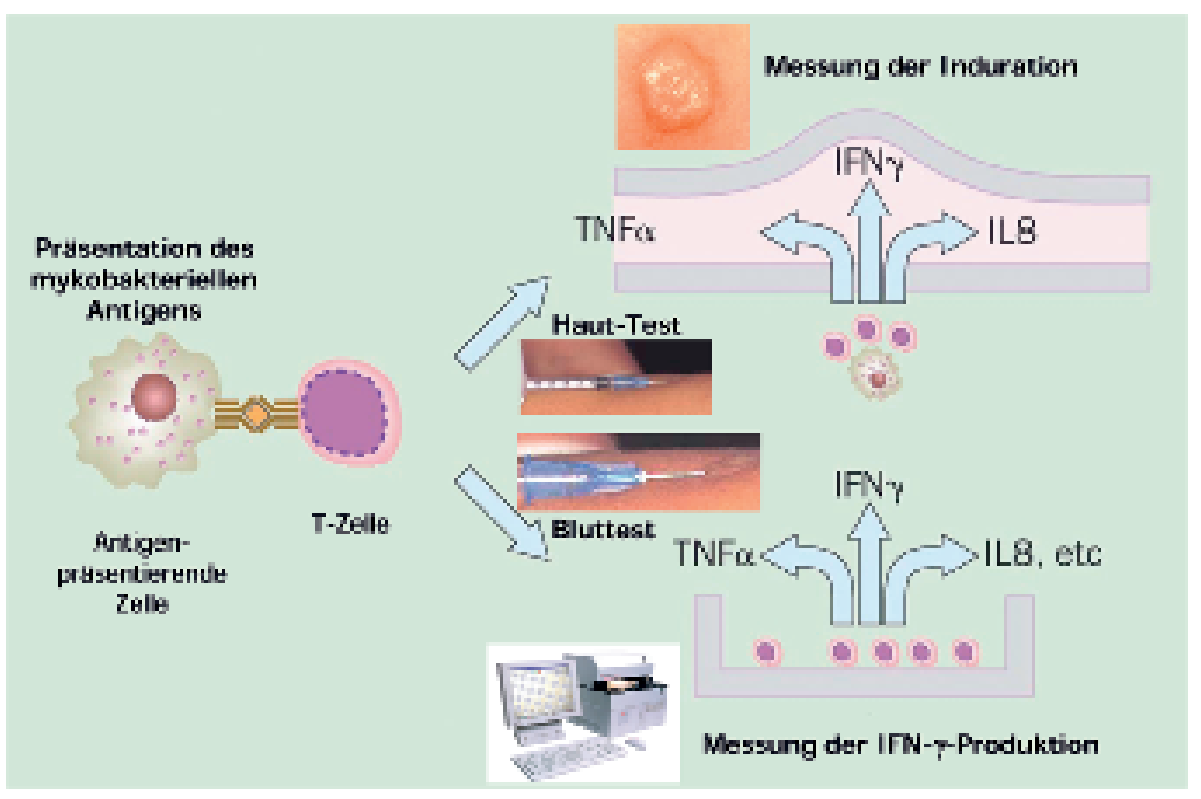

Abb. 1 Biologische Basis der Tuberkulinhauttests (THT) und der Interferon- $\gamma$ (IFN$\gamma$ )-Tests. Modifiziert nach Lancet Infect Dis 2004; Vo. 4: 761 - 767, mit freundlicher Genehmigung. 
einer zellvermittelten Immunantwort Zytokine, darunter Interferon $-\gamma$, sezernieren. Immunologische Testverfahren machen sich die Interferon- $\gamma$-Produktion von CD4-Zellen nach in vitroStimulation mit spezifischen Antigenen zunutze (Abb.1 und Abb. 2). Erstmals nach Entdeckung des Tuberkulins durch Robert Koch im Jahre 1890 eröffnen diese Testverfahren quantitative diagnostische Möglichkeiten zum Nachweis einer LTBI. In den aktuellen Entwürfen US-amerikanischer und britischer Empfehlungen werden diese in vitro-Testverfahren als ergänzende Methode zur Diagnostik einer LTBI bereits angeführt. Der Prozess der Bewertung bzw. die Erarbeitung klarer Indikationen kann jedoch keinesfalls als abgeschlossen betrachtet werden $[11,12]$.

Im Folgenden sollen die Funktionsweise der in Deutschland verfügbaren Tests (gemäß den Herstellerangaben), die aktuelle Datenlage zu IFN- $\gamma$-Testverfahren und unbeantwortete Fragestellungen dargestellt und der gegenwärtige Stellenwert dieser neuen Methoden aufgezeigt werden. Hinsichtlich der Studienlage bezieht sich dieser Beitrag im Wesentlichen auf einen umfassenden systematischen Übersichtsartikel von Pai u. Mitarb. [13], ergänzend werden relevante aktuelle Studien berücksichtigt.

\section{QuantiFERON $^{\circledR}$-TB Gold}

Der QuantiFERON ${ }^{\circledR}$-TB Gold Test ist eine Weiterentwicklung des QuantiFERON ${ }^{\circledR}$-TB-Tests, letzterer wurde 2001 [14], der TB Gold Test im Dezember 2004 [15] von der amerikanischen Food and

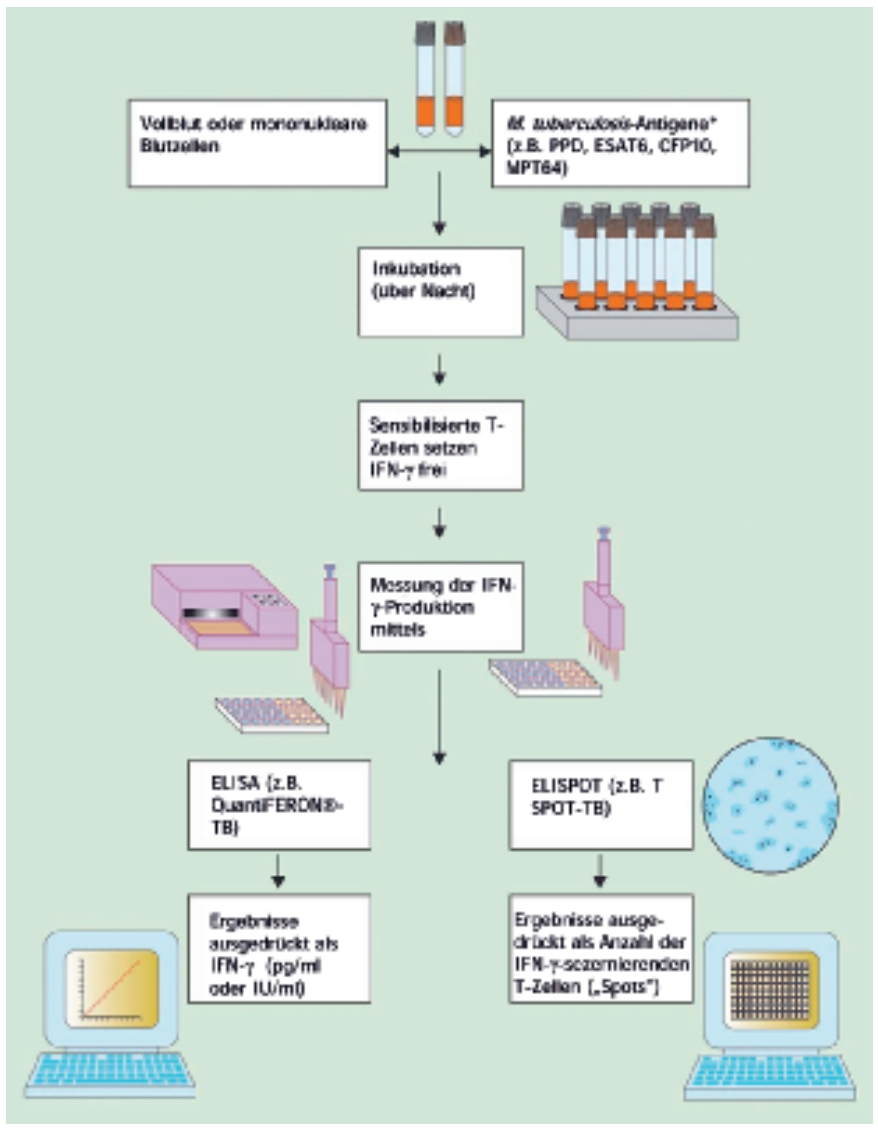

Abb. 2 Überblick über die IFN- $\gamma$-Test-Technologie. Nach Lancet Infect Dis 2004; Vol. 4: 761 - 767, mit freundlicher Genehmigung.

*PPD = purified protein derivative
Drug Administration (FDA) in den USA als diagnostisches Verfahren für bestimmte Fragestellungen im Zusammenhang mit der LTBI zugelassen. Darüber hinaus liegt die CE-Zertifizierung vor [16]. Er wird von Cellestis (Carnegie Victoria, Australien; früher Cellestis Limited) hergestellt (www.cellestis.com) und in Europa von Cellestis Europe mit Sitz in Darmstadt, Deutschland, vertrieben. Grundprinzip ist die quantitative Messung der Interferon$\gamma$-Abgabe sensibilisierter Lymphozyten im Vollblut mittels ELISA (Enzyme-Linked Immunosorbent Assay) nach Zugabe von Antigen und Inkubation über Nacht.

Während beim QuantiFERON ${ }^{\circledR}$-TB-Test als stimulierendes Antigen PPD (purified protein derivative von M. tuberculosis und $M$. avium [14]) und damit eine Mischung aus verschiedenen Proteinen verwendet wurde, werden beim Nachfolgeprodukt, dem QuantiFERON ${ }^{\circledR}$-TB Gold Test, nun spezifischere synthetische Peptide, die die Aminosäuresequenz der Proteine der RD1-Region (region of difference 1) ESAT-6 (early secreted antigenic target $6 \mathrm{kD}$ protein) und CPF-10 (culture filtrate protein 10) abdecken, eingesetzt. Bei der dritten Generation, dem QuantiFERON ${ }^{\circledR}$-TB Gold In-Tube Test, werden zusätzlich Peptide des Proteins TB7.7(p4) verwendet. Beim In-Tube-Test sind die Blutabnahmeröhrchen bereits mit Antigen beschichtet, womit die Verarbeitungsschritte vor der Inkubation weiter reduziert und vereinfacht werden konnten. Die genannten Antigene sind nicht bei M. bovis BCG vorhanden, da diesem der genetische Abschnitt der RD1-Region fehlt. Aus diesem Grund soll das Testresultat, anders als beim Tuberkulinhauttest, durch eine stattgehabte BCGImpfung nicht beeinflusst werden [17]. Auch bei den meisten Umweltmykobakterien finden sich die verwendeten Antigene nicht, Ausnahmen sind nach Angaben des Herstellers [18] jedoch M. kansasii, M. szulgai, M. marinum, und M. flaveszens.

Bei der ersten, nicht mehr erhältlichen, Testgeneration (PPDQuantiFERON $^{\circledR}$ ) war die Testinterpretation verhältnismäßig kompliziert. Das Resultat wurde unter Berücksichtigung des individuellen Risikos anhand verschiedener Messparameter unter Anwendung unterschiedlicher cut-offs bewertet $[12,14]$. Die Übereinstimmung mit dem Tuberkulinhauttest variierte je nach Studienpopulation deutlich (40-100\%) [19], problematisch war insbesondere die mögliche Kreuzreaktion bei BCG-Geimpften. Der weiterentwickelte Test ist in seiner Interpretation deutlich vereinfacht worden. Basierend auf einem vom Hersteller empfohlenen einheitlichen cut-off ergibt sich nunmehr ein einfaches „positives“ bzw. „negatives“ Resultat. Die folgenden Ausführungen konzentrieren sich auf das aktuellste Produkt, den QuantiFERON $^{\circledR}$-TB Gold In-Tube Test [18], für den QuantiFERON ${ }^{\circledR}$-TB Gold Test wird auf weiterführende Informationen des Herstellers verwiesen [20] (www.cellestis.com).

Anzumerken ist, dass die aktuelleren Studien fast ausschließlich mit dem QuantiFERON ${ }^{\circledR}$-TB Gold Test durchgeführt wurden. Daten zur Übereinstimmung mit der In-Tube Methode sind bislang noch nicht publiziert. Zurzeit werden nach Angaben von Cellestis allerdings 30 bis 40 Studien ausschließlich mit dem QuantiFERON $^{\circledR}$-TB Gold In-Tube Test durchgeführt (pers. Mitteilung Hr. Stöckigt/Cellestis; 23.9.2005). 
Die einzelnen Arbeitsschritte der Blutentnahme und des ELISA sind in Abb. 3 dargestellt. Mittels venöser Blutentnahme, am besten mit einem Vakuum-Blutabnahmesystem, wird direkt und möglichst exakt $1 \mathrm{ml}$ Vollblut in jedes der beiden Teströhrchen (heparinisierte Vakuetten) gefüllt (eine Validierung erfolgte für Probenvolumina zwischen 0,8 und 1,2 ml). Eines der Röhrchen ist mit TB-spezifischen Antigenen beschichtet, das andere Röhrchen dient als negative Kontrollprobe ohne Antigen („Nil-control tube“), sie können anhand der Deckelfarben und Etikettenfarben unterschieden werden. Die negative Kontrollprobe gleicht die Hintergrundsignale aus, die durch die Effekte heterophiler Antikörper und durch nicht-spezifisches Interferon- $\gamma$ in den Blutproben verursacht werden. Alternativ kann zusätzlich eine Positivkontrolle (Mitogenröhrchen, blauer Deckel) in Abhängigkeit des zu testenden Patienten (z. B. bei immunsupprimierten Patienten) mitanalysiert werden. Dadurch soll bei kritischen Fragestellungen die Aussagekraft und damit die Qualität des Testverfahrens deutlich erhöht werden. Die Röhrchen werden entweder 8-10-mal hin- und hergeschwenkt oder 5 Sekunden lang geschüttelt. So bald wie möglich, jedoch innerhalb von maximal 16 Stunden (Aufbewahrung bei Raumtemperatur), werden die Röhrchen in aufrechter Position für 16-24 Stunden bei 37 Grad Celsius inkubiert (bevorzugt über Nacht). Sollte die Inkubation nicht unmittelbar nach der Blutentnahme erfolgen, so müssen die Röhrchen erneut hin- und hergeschwenkt bzw. erneut geschüttelt werden. Der Hersteller bietet zu diesem Zweck auch einen mobilen Inkubator an, so dass dieser Methodenschritt auch außerhalb eines Labors erfolgen kann. Der Transport ins Labor soll innerhalb von drei Tagen bei einer Temperatur von 2-27 Grad Celsius erfolgen, ein Transport auf Eis ist nicht zulässig. Anschließend wird das Röhrchen zentrifugiert (5-10 Minuten bei 1500 - 2200 RCF [g, relativer Zentrifugalkraft, nicht RPM: Umdrehungen pro Minute]) und das Plasma gewonnen. Die abzentrifugierten Röhrchen können vor Abnahme des Plasmas bei 2-8 Grad Celsius für 14 Tage gelagert werden. Das abgenommene Plasma kann bei 2-8 Grad Celsius maximal 8 Wochen gelagert werden. Alternativ kann das Plasma bei mindestens -20 Grad Celsius für längere Zeiträume eingefroren werden. Um die Wahrscheinlichkeit des Verklumpens zu reduzieren, wird eine Temperatur von - 70 Grad Celsius empfohlen. Nach Plasmaentnahme (mind. $200 \mu \mathrm{l}$ ) wird daraus mittels ELISA durch Verwendung anti-humaner monoklonaler IFN- $\gamma$-Mäuseantikörper nach Zugabe eines Enzymsubstrates quantitativ die Interferon- $\gamma$-Menge bestimmt. Die Testergebnisse werden in internationalen Einheiten in Relation zur Interferon- $\gamma$-Referenzzubereitung angegeben, sie werden durch Abzug des Interferon- $\gamma$-Wertes in der negativen Kontrollprobe korrigiert.

Ergebnisauswertung und Interpretation erfolgen mithilfe einer speziellen Software (Anwendungsprogramm). Als positiv wird ein Ergebnis mit einem cut-off von $\geq 0,35 \mathrm{IU} / \mathrm{ml}$ und einem korrigierten TB-Antigen-Wert, der mind. 25\% über dem ermittelten Nil-Wert liegt, gewertet, bei positivem Resultat empfiehlt der Hersteller die Durchführung zweier Bestätigungstests an der Original-Plasmaprobe. Dabei kann es zu einer Abweichung des Testergebnisses um $\pm 15 \%$ kommen (Variationskoeffizient). Die Höhe des Wertes lässt keine Aussagen zum Stadium oder der Ausprägung der Infektion, dem Ausmaß der Immunreaktion oder dem Risiko eines Fortschreitens in eine behandlungsbedürftige Tuberkulose zu.

Hinsichtlich des Zeitaufwandes werden nach Herstellerangaben [18] 2-5 Minuten für die Blutentnahme, gefolgt von 16-24 Stunden Inkubation und circa 3 Stunden für eine ELISA-Platte mit 44, 56 oder 88 Proben, je nach Verfahrensweise (etwa 1-1,5 Stunden reine Arbeitszeit), veranschlagt, für jede weitere Platte ergibt sich ein zusätzlicher Zeitaufwand von 10-15 Minuten. Theoretisch kann daher bereits am Tag nach der Blutentnahme mit einem Testergebnis gerechnet werden. Die Teströhrchen müssen bei 4-25 Grad Celsius, die Test-Kits bei 2-8 Grad Celsius aufbewahrt werden. Die Haltbarkeit beträgt bei korrekter Aufbewahrung für die Blutprobenröhrchen 15 Monate, für den ELISA-Kit 3 Jahre ab Herstellungsdatum. Für die angesetzten Testlösungen gelten die vom Hersteller genannten Aufbewahrungsbe-
Schritt I - Inkubation und Plasmagewinnung
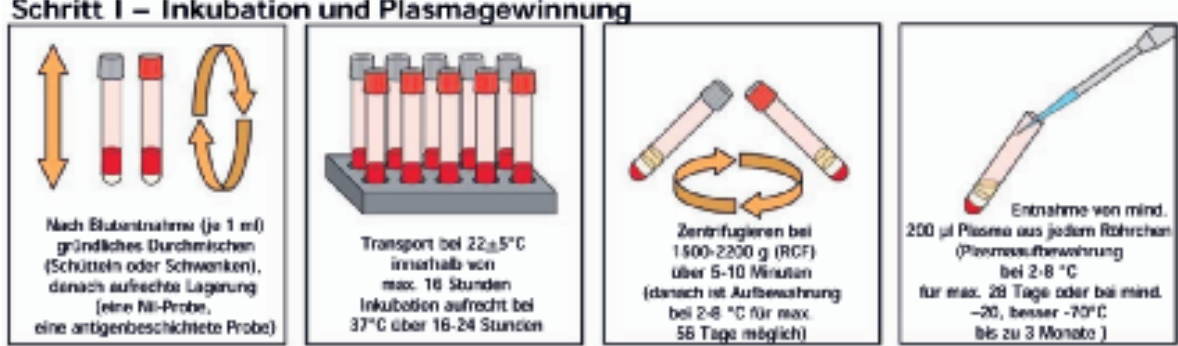

Schritt II - IFN-y ELISA
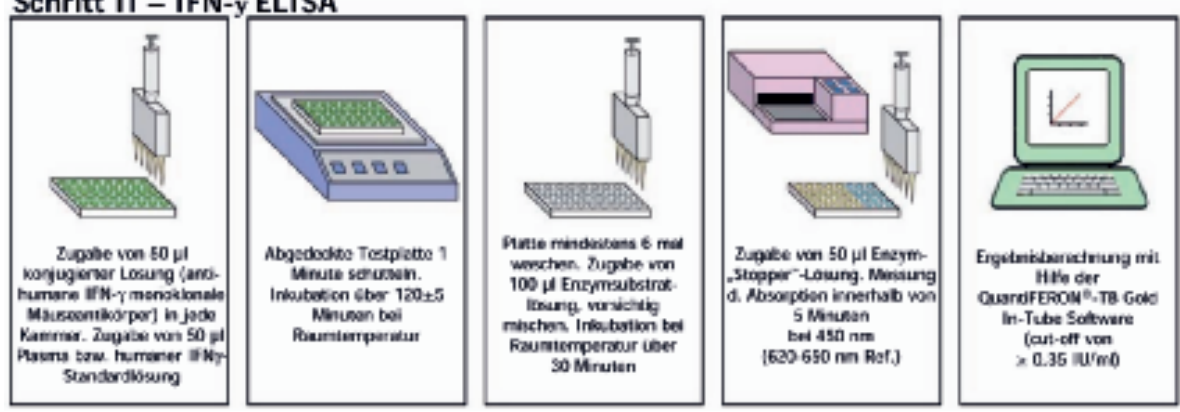

Abb. 3 Funktionsweise des QuantiFERON $^{\circledR}$-TB-Gold In-Tube. Modifiziert nach Cellestis Manual nach persönl. Kommunikation mit Herrn Lebeau, Cellestis. 
dingungen und Haltbarkeitsfristen [18]. Hinsichtlich der Laborausstattung wird in Deutschland ein Standardarbeitsplatz, in den USA ein Biohazard-tauglicher Arbeitsplatz der Klasse II empfohlen.

Die Materialkosten für QuantiFERON ${ }^{\circledR}$-TB Gold In-Tube belaufen sich laut Hersteller für einen ELISA Test-Kit (mit Reagentien für 192 Reaktionen und 2 Mikrotiterplatten) auf 550 Euro, für je 100 Röhrchen zur Blutabnahme der Null und TB-Antigen-Probe auf insgesamt 600 Euro und für 100 Mitogenröhrchen für die oben genannten zusätzlichen Auswertungen auf 150 Euro. Dadurch ergeben sich Materialkosten von circa 12,50 Euro (ohne Mitogenkontrolle) und circa 18,50 Euro (mit zusätzlicher Mitogenkontrolle) pro untersuchte Person (pers. Mitteilung Hr. Stöckigt/Cellestis, 23.9.2005). Dazu kommen Transport-, Laborund Personalkosten.

\section{T SPOT-TB}

Der wesentliche Unterschied des T SPOT-TB zum QuantiFERON $^{\circledR}$-Test ist, dass hier mithilfe eines vereinfachten ELISPOTVerfahrens (Enzyme-Linked Immunospot Assay) die Anzahl IFN$\gamma$-produzierender sensibilisierter Effektor-T-Zellen als Anteil einer determinierten Zahl von aus dem Vollblut separierten peripheren mononukleären Zellen (PBMC = peripheral blood mononuclear cells) gemessen werden soll [21]. Die IFN- $\gamma$-Produktion wird über die Zugabe von Peptid-Antigenen zu den PBMC's angeregt. Der T SPOT-TB Test wurde, ähnlich wie der QuantiFERON $^{\circledR}$-Test, ebenfalls aus einem Testverfahren entwickelt, welches initial als stimulierendes Antigen PPD verwendete (namens ELISPOT; zu PPD s. o.). Die neueste Testgeneration verwendet als Antigene ESAT-6- und CFP-10-Peptide. Hersteller ist Oxford Immunotec Limited in Abingdon, Oxfordshire, Großbritannien (www.oxfordimmunotec.com), auch hier liegt die CE-Zertifizierung vor [16].

\section{Durchführung des T SPOT-TB}

Abb. 4 zeigt die einzelnen Arbeitsschritte der Durchführung des T SPOT-TB Tests. Zur Blutentnahme werden spezielle Blutentnahmeröhrchen verwendet für die Trennung der Lymphozyten von den übrigen Zellen. Der Hersteller empfiehlt BD Vacutainer $^{\mathrm{TM}} \mathrm{CPT}^{\mathrm{TM}}$ (BD, www.bd.com, etwa 4 Euro pro Röhrchen). Verfügbar sind Röhrchen mit $4 \mathrm{ml}$ (für Kleinkinder) und $8 \mathrm{ml}$ Volumen. Bei Verwendung des $4 \mathrm{ml}$-Röhrchens müssen mindestens $3 \mathrm{ml}$, für das $8 \mathrm{ml}$-Röhrchen mindestens $6 \mathrm{ml}$ Blut abgenommen werden. Alternativ können Li-Heparin-Röhrchen verwendet werden. Nach vorsichtigem Mischen (5-mal schwenken, auf keinen Fall schütteln) muss das Röhrchen schnellstmöglich (nach neuen Erkenntnissen kann nach Angaben des Herstellers auch eine zeitliche Verzögerung von mehreren Stunden [über Nacht] hinsichtlich geringer Sensitivitätsverluste toleriert werden [persönl. Mitteilung Frau Schneegans/Oxford Immunotec, 12.9.2005]) bei 18-25 Grad Celsius in das Labor transportiert werden. Dort wird (direkt vor dem Testansatz, günstigstenfalls innerhalb von zwei Stunden nach Blutentnahme) mindestens 20 Minuten bei $1500-1800 \mathrm{~g}$ zentrifugiert (genaue Dauer und bevorzugte Gravitationskraft richten sich nach dem Blutvolumen). Die so gewonnenen mononukleären Zellen sollten dann baldmöglichst vorsichtig abpipettiert werden. Ist ein Transport vorgesehen, so sollte das komplette Vollblut verschickt werden, um die Lebensfähigkeit der Zellen zu sichern (max. 24 Stunden) [persönl. Mitteilung Frau Schneegans/Oxford Immunotec, 12.9.2005].

Nach einem speziellen Waschvorgang werden die Zellen automatisiert gezählt und jeweils $2,5 \times 10^{5} \mathrm{PBMCs}$ (entsprechend einer einschichtigen „Zell-Lage“) in Mikrotiterplattenvertiefungen (,Wells“) gegeben, welche mit einer IFN- $\gamma$-Antikörper (Maus)beschichteten Membran ausgekleidet sind. Pro Mikrotiterplatte können 24 Testreihen durchgeführt werden. Antigen-Panel A und B sowie Kontrollen werden in die Vertiefungen hinzugefügt und mit den PBMCs über 16-20 Stunden bei 37 Grad Celsius in-

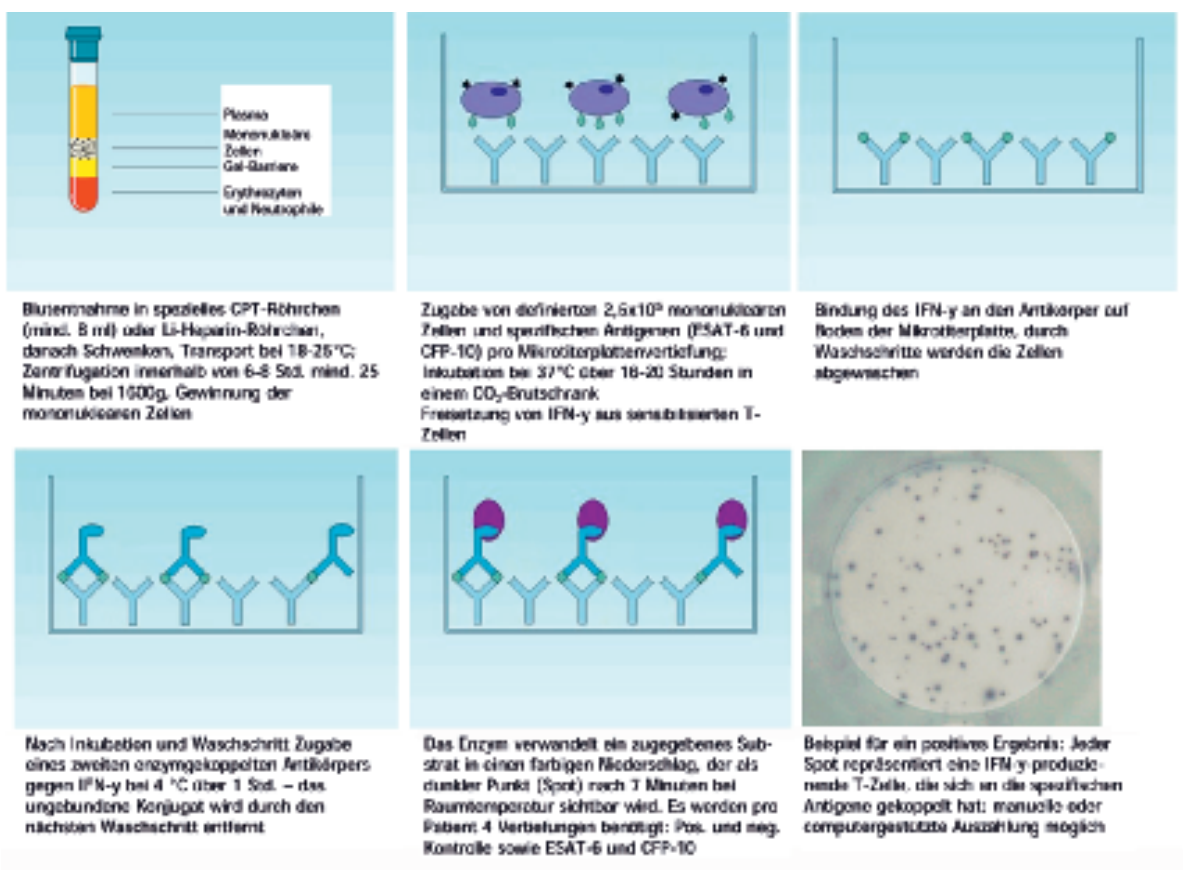

Abb. 4 Funktionsweise der T SPOT ${ }^{\mathrm{TM}}$-Technologie. Modifiziert nach Oxford Immunotec Manual nach persönl. Kommunikation mit Frau Schneegans, Oxford Immunotec. 
kubiert, um eine Stimulation von vorhandenen aktivierten T-Zellen zu ermöglichen. Sezerniertes IFN- $\gamma$ wird durch die in der Beschichtung enthaltenen Antikörper eingefangen und die Zellen sowie sonstiges unerwünschtes Material durch viermaliges Spülen entfernt. Dann wird ein zweiter Antikörper zugegeben, der an alkalische Phosphatase konjugiert und auf ein anderes Epitop auf dem IFN- $\gamma$-Molekül ausgerichtet ist. Dabei wird bei 2-8 Grad Celsius über 60 Minuten inkubiert. Der Antikörper bindet an das auf der Well-Oberfläche eingefangene IFN- $\gamma$, das ungebundene Konjugat wird durch viermaliges Spülen entfernt. Ein dann zugegebenes lösliches Substrat wird durch gebundenes Enzym gespalten und bildet am Ort der Entstehung einen Punkt („Spot“) aus unlöslichem Präzipitat (Inkubation bei Raumtemperatur über sieben Minuten, danach vorsichtiges Ausspülen der Vertiefungen). Jeder Spot soll mit einer Zytokin-produzierenden Zelle korrespondieren, die Ermittlung der Spot-Zahl liefert daher ein Maß für die Menge von $M$. tuberculosis-sensibilisierten T-Lymphozyten. Als cut-off für ein positives Ergebnis gelten $\geq 6$ Spots. Bei spontaner IFN- $\gamma$-Sekretion in der Kontrolle ( $\geq 6$ Spots; dies tritt bei ca. 1-2\% der Testpersonen auf [persönl. Mitteilung Chris Granger/Oxford Immunotec, 21.10.2004]) wird eine mindestens doppelte Spotanzahl als positiver Befund gewertet. Bei einer Spotzahl von über 10 in der Negativ-Kontrolle sind die Ergebnisse schwer zu interpretieren (vgl. dt. Packungsbeilage S. 11, Qualitätskontrolle). Die Positiv-Kontrolle sollte mindestens 20 Spots enthalten. Die Auswertung erfolgt manuell und kann auch automatisiert werden. Bei Verdacht auf Artefakte wird die visuelle Kontrolle empfohlen.

Das ungeöffnete Test-Kit ist bei 2-8 Grad Celsius zu lagern und soll nach dem angegebenen Verfallsdatum nicht mehr verwendet werden. Die Haltbarkeit liegt bei mindestens sechs Monaten. Unterschiedliche Pipettier- und Spültechniken, Inkubationszeiten und/oder -temperaturen können sich auf die konkreten Ergebnisse auswirken. Auch die Zahl der in jede Vertiefung gegebenen Zellen muss korrekt sein. Hinsichtlich der Laborausstattung wird auch hier ein Biohazard-tauglicher Arbeitsplatz der Klasse II empfohlen. Das Test-Kit kann durch eine Abdeckung der nichtgenutzten Vertiefungen vier- bis fünfmal weiter benutzt werden. Es stehen in Kürze brechbare Riegel zur Verfügung.

Hinsichtlich des Zeitaufwandes müssen ca. 45 Minuten für die Gewinnung der Lymphozyten, 16-20 Stunden für die Inkubation und 1,5 bis 2 Stunden für die Durchführung des ELISA veranschlagt werden. Die reine Arbeitszeit beträgt circa 1-1,5 Stunden.

Die Materialkosten für den T SPOT-TB-Test belaufen sich nach Auskunft des Herstellers für ein Test-Kit auf 900 Euro (persönliche Mitteilung Frau Schneegans am 12.09.2005), bei maximal 24 Tests pro Kit ergeben sich dann Kosten von 37,50 Euro pro untersuchte Person. Hinzu kommen Transport-, Labor- und Personalkosten.

\section{Studienlage}

Einen umfassenden Überblick über die bis August 2004 durchgeführten relevanten und sehr heterogenen Studien bietet ein systematisches Review von Pai u. Mitarb. [13], in welchem die Autoren 75 IFN- $\gamma$-Test-Studien evaluiert haben. Eine weitere, jedoch weniger detaillierte Übersichtsarbeit haben Dheda u. Mitarb. verfasst [16], wobei die Autoren ähnliche Rückschlüsse ziehen wie die Autorengruppe um Pai. Im Wesentlichen lassen sich die dort zitierten Untersuchungen folgendermaßen unterteilen:

\section{In Studien}

- an Personen, die nachweislich an behandlungsbedürftiger Tuberkulose erkrankt sind (bakteriologisch bestätigte, vorwiegend pulmonale Tuberkulosen)

- an vermutlich gesunden, d.h. nicht-infizierten oder erkrankten (Kontroll-)Personen

- an BCG-geimpften, gesunden Personen

- an Personen mit bakteriologisch bestätigten Umweltmykobakteriosen

- im Rahmen von Umgebungsuntersuchungen mit Berücksichtigung der Expositionsdauer und -intensität.

Eine aktuelle Studie einer italienischen Arbeitsgruppe hat erstmals den QuantiFERON ${ }^{\circledR}$-TB Gold auch an einem unselektierten Patientengut eines Krankenhauses in Modena untersucht [22].

Aufgrund der Heterogenität der Studien sind direkte Vergleiche schwierig $[13,16]$. Bei der Bewertung der Studienergebnisse sind folgende Aspekte zu beachten:

- Art und „Generation“ des untersuchten IFN- $\gamma$-Tests

(In-house-Test, standardisierte Protokolle)

- Verwendete Antigene (PPD, isoliert oder kombinierte RD1-Antigene)

- angewandte cut-offs

- verfahrenstechnische Details (z.B. Inkubationszeiten, Zeitfenster zwischen Blutentnahme und Weiterverarbeitung im Labor, Verwendung von gefrorenen Blutproben)

- Studienpopulation (behandlungsbedürftige TB, pulmonale und/oder extrapulmonale TB, Kontaktpersonen, Zugehörigkeit zu TB-Risikogruppen, HIV-Status, Impfstatus, Alter, gesunde Personen, Personen mit pneumologischen und/oder anderen Erkrankungen)

- verwendete Referenzmethode (THT: nach Mendel-Mantoux, Heaf-Test ${ }^{1}$; cut-offs, verwendetes Tuberkulin und Dosierung)

- Messung des Expositionsausmaßes (Intensität und Dauer der Exposition)

- Follow-up der untersuchten Population und Vorhersagekraft bezüglich der Entwicklung einer behandlungsbedürftigen Tuberkulose

- Therapiestatus und Dauer der Therapie

- Reproduzierbarkeit der gemessenen Ergebnisse

- Fallzahlen/statistische Aussagekraft

- Übertragbarkeit der Ergebnisse auf andere Studienpopulationen

\footnotetext{
${ }^{1}$ Beim Heaf-Test handelt es sich um eine überwiegend in Großbritannien verwendete Multipunkturmethode, mit der unter Verwendung eines speziellen Applikators Tuberkulin in die Haut eingebracht wird [23].
} 
Tab. 1 gibt eine Übersicht über die jeweilige Anzahl der von Pai ausgewerteten IFN- $\gamma$-Studien nach entsprechender klinischer Fragestellung [13], welche im Folgenden für die immunologischen Testverfahren, auch unter Berücksichtigung aktueller Studien, beleuchtet werden sollen. Grundsätzlich muss betont werden, dass angesichts der Fülle der Publikationen und nahezu wöchentlicher Neuveröffentlichungen weltweit gewonnener Studiendaten diese Übersichtsarbeit nur eine Momentaufnahme darstellen und keinen Anspruch auf Vollständigkeit erheben kann.

Die im Weiteren verwendete Benennung der Testverfahren entspricht der in der jeweiligen Veröffentlichung gewählten Bezeichnung, da nicht immer klar hervorgeht, ob die geschilderten zertifizierten Verfahren, „Vorläuferversionen“ oder In-houseTests angewendet wurden. Das bedeutet, dass „RD1-ELISPOT“ nicht zwangsläufig dem T SPOT-TB und „RD1-QuantiFERON“ nicht dem QuantiFERON ${ }^{\circledR}$ Gold Test gleichgesetzt werden kann.

\section{Sensitivität bei behandlungsbedürftiger Tuberkulose}

Sensitivität bedeutet der Anteil der Personen mit Erkrankung an behandlungsbedürftiger Tuberkulose (bzw. LTBI), welche einen positiven IFN- $\gamma$-Test aufweisen. Pai u. Mitarb. [13] fanden 29 Studien, welche die Sensitivität von IFN- $\gamma$-Testen bei bakteriologisch (kulturell oder mikroskopisch) bestätigten, überwiegend HIV-negativen Tuberkulosepatienten, untersuchten - oftmals vergleichend mit dem THT. Dabei zeigten die vergleichenden Studien, welche jedoch häufig auf PPD basierende IFN- $\gamma$-Tests verwendeten, für den THT eine höhere Sensitivität. Auf PPD basierende IFN- $\gamma$-Tests wiesen in den Studien eine größere Sensitivität auf als solche, welche isoliert die Reaktion auf ESAT-6 und/ oder CFP-10 bestimmten. Bei Verwendung eines Antigen-„,Cocktails“ (ESAT-6 + CFP-10) wurden jedoch gleichwertige oder bessere Sensitivitätswerte erreicht. Grundsätzlich lag die Sensitivität bei unbehandelten Patienten höher als bei anbehandelten.

Mit der zweiten Generation des QuantiFERON ${ }^{\circledR}$-Tests (kombinierte Berücksichtigung der Reaktion auf ESAT-6 und CFP-10) wurden die besten Sensitivitätswerte für unbehandelte bzw.

Tab. 1 IFN- $\gamma$-Tests: Klinische Fragestellungen und Anzahl der Studien, welche diese untersuchen (nach [13])

\begin{tabular}{lc}
\hline Klinische Fragestellung & $\begin{array}{l}\text { Anzahl der } \\
\text { Studien }\end{array}$ \\
& 29 \\
\hline $\begin{array}{l}\text { Sensitivität bei behandlungsbedürftiger Tuberkulose und } \\
\text { Vergleichbarkeit mit THT? }\end{array}$ & 22 \\
\hline $\begin{array}{l}\text { Spezifität bei gesunden Personen mit geringem TB-Risiko } \\
\text { und Vergleichbarkeit mit THT? }\end{array}$ & 11 \\
$\begin{array}{l}\text { Sensitivität bei Verdacht auf LTBI? } \\
\text { Übereinstimmung mit THT (Gründe für Diskordanz)? }\end{array}$ & $16(3)$ \\
\hline $\begin{array}{l}\text { bessere Korrelation mit Exposition als der THT? } \\
\text { geringere Beeinflussung durch BCG-Impfung als der THT? }\end{array}$ & 12 \\
\hline $\begin{array}{l}\text { geringere Beeinflussung durch Umweltmykobakterien als } \\
\text { der THT? }\end{array}$ & 4 \\
\hline $\begin{array}{l}\text { Vorhersage des Erkrankungsrisikos bei LTBI möglich? } \\
\text { Einfluss medikamentöser Behandlung? }\end{array}$ & 1 \\
\hline Reproduzierbarkeit der Testergebnisse? & 5 \\
\hline
\end{tabular}

THT = Tuberkulinhauttest, LTBI = latente tuberkulöse Infektion kürzer als eine Woche behandelte Tuberkulosepatienten erreicht. Die Sensitivitäten lagen hierbei zwischen 83 und $89 \%$ $[24,25]$. In der Studie von Mori u. Mitarb. [25] an 118 kulturell bestätigten Tuberkulosen lag die Sensitivität des THT (japanisches Tuberkulin, äquivalent zu 3 TU PPD-S; cut-off $5 \mathrm{~mm}$ ) mit 66\% dabei deutlich niedriger im Vergleich zum QuantiFERON $^{\circledR}$-Test (ESAT-6/CFP-10) mit 89\%.

In einer 2005 veröffentlichten Studie von Ravn u. Mitarb. [26] wurde ebenfalls der RD1-QuantiFERON ${ }^{\circledR}$-Test bei Patienten mit Verdacht auf aktive Tuberkulose verwendet. Die Sensitivität bei bakteriologisch bzw. bei klinisch im Verlauf bestätigten Tuberkulosen (pulmonal und extrapulmonal) übertraf mit 85\% (40/48; KI 75-96) signifikant die der Mikroskopie (42\%; 20/48, KI 27 - 56) und der Kultur (59\%; 27/46; KI 44 - 73). Für ausschließlich pulmonale Tuberkulosen fand sich kein Unterschied hinsichtlich der Sensitivität für IFN- $\gamma$-Test und Kultur. Für die extrapulmonalen Tuberkulosen wurde eine Sensitivität des IFN$\gamma$-Tests von $92 \%$ beobachtet (allerdings bei kleiner Patientenzahl von $n=13$ ). Die höchste Sensitivität für alle Fälle ergab sich bei Kombination aller diagnostischer Methoden (96\%; KI 90-102).

Auch mit dem ELISPOT-Verfahren werden unter Verwendung von ESAT-6 und CFP-10 die höchsten Sensitivitäten erreicht. So fanden Chapman u. Mitarb. [27] in Sambia bei 50 Patienten (unbehandelt oder < 1 Monat Therapie; 39 HIV-positiv) für die HIVnegativen Patienten eine Sensitivität von $100 \%$ und für die HIVpositiven Personen von $90 \%$.

\section{Sensitivität der IFN- $\gamma$-Tests bei vermuteter latenter tuberkulöser Infektion}

Pai u. Mitarb. betrachteten unter dem Aspekt der Sensitivität bei LTBI 11 IFN- $\gamma$-Teststudien (darunter zwei mit QuantiFERON ${ }^{\circledR}$ [PPD] und vier mit T SPOT-TB [2×PPD+ESAT-6; $1 \times$ ESAT-6; $1 \times$ ESAT-6 + CFP-10], bei den übrigen handelte es sich um „Inhouse“ Tests mit langen Inkubationszeiten [ $5 \times$ ELISA, $1 \times$ ELISPOT]) [13]. Untersucht wurden symptomfreie, THT-positive Personen mit stattgehabter TB-Exposition (Haushaltskontakte, berufliche Exposition). Die PPD-basierten Testverfahren ergaben Sensitivitäten von über $80 \%$, bei Verwendung von RD1-Antigenen (teilweise aber nur isolierte und nicht kombinierte Bestimmung, s. o.) zeigten sich lediglich bei vier von neun Studien Sensitivitäten über $80 \%$. Im direkten Vergleich zu RD1-basierten Tests wurden mit den PPD-basierten Testverfahren höhere Sensitivitätswerte erreicht.

\section{Spezifität der IFN- $\gamma$-Tests bei - angenommen - gesunden Testpersonen}

Die Spezifität beschreibt den Anteil der gesunden (d.h. nicht mit M. tuberculosis infizierten bzw. an Tuberkulose erkrankten) Personen, welche im IFN- $\gamma$-Test eine negative Testreaktion zeigen. In den von Pai u. Mitarb. [13] angeführten 22 Studien wurden in der Regel gesunde Studienteilnehmer aus Niedrigprävalenzländern ohne bekannte Tuberkulose-Exposition untersucht. In Studien, welche IFN- $\gamma$-Tests (PPD, ESAT-6 und/oder CFP-10) mit dem THT verglichen, waren die Spezifitäten in den meisten Studien vergleichbar, aber durchaus variabel ( $85-100 \%)$. Grundsätzlich waren die Spezifitätsraten der RD1-IFN- $\gamma$-Tests für BCG-Geimpfte deutlich höher als die des THT und der PPD-IFN$\gamma$-Tests und lagen meist weit über 90 , häufig sogar bei $100 \%$ 
$[17,24,25,27,28]$. Ravn u. Mitarb. fanden bei 39 gesunden, nicht exponierten dänischen Personen bei Verwendung des RD1-QuantiFERON ${ }^{\circledR}$-Tests eine Spezifität von 97\% [29].

\section{Übereinstimmung Tuberkulinhauttest und IFN- $\boldsymbol{\gamma}$-Tests}

Pai u. Mitarb. fanden 16 Studien, welche die Übereinstimmung der IFN- $\gamma$-Tests mit dem THT an sehr unterschiedlicher Studienklientel untersuchten. In den meisten Studien wurde eine mäßige Übereinstimmung von $60-80 \%$ beobachtet. Lediglich drei Studien forschten nach Gründen für diskordante Ergebnisse: Mazurek u. Mitarb. [30] untersuchten den QuantiFERON ${ }^{\circledR}$-TB Test (PPD) vergleichend (5 TU PPD-S, risikostratifizierte cut-offs) im Rahmen einer Multicenterstudie an 1226 Erwachsenen mit unterschiedlichem Infektionsrisiko. Für die gesamte Gruppe ergab sich eine Übereinstimmung des THT mit dem IFN- $\gamma$-Test von $83 \%(\kappa=0,60)$. In einer multivariaten Analyse lag die odds ratio für unterschiedliche Testergebnisse (d.h. positiver THT, negativer IFN- $\gamma$-Test) bei BCG-Geimpften sieben mal höher als bei Ungeimpften.

Auch Fietta und Mitarbeiter [31] prüften den QuantiFERON ${ }^{\circledR}$-TB Test (PPD) an Personen mit unterschiedlichem Risiko $(n=258)$. Für die gesamte Studienpopulation betrug die Übereinstimmung mit dem THT-Ergebnis ( 5 TU Biocine Test PPD, risikostratifizierte cut-offs) $78 \%(\kappa=0,58)$. Die Übereinstimmung war geringer bei Personen mit aktiver Tuberkulose $(\kappa=0,25)$. Hier lag allerdings die Sensitivität des IFN- $\gamma$-Tests mit $91 \%$ deutlich über der des THT mit 65\%. Die Mehrheit der Patienten mit diskrepanten Testergebnissen (IFN- $\gamma$-Test positiv/THT negativ) hatte mindestens einen Risikofaktor für Tuberkulose, welcher zugleich häufig einen falsch-negativen THT verursacht, so beispielsweise hohes Lebensalter, Hepatitis C, Alkoholkrankheit, Nierenversagen, Kortikosteroidtherapie und Tumorleiden.

Ewer und Mitarbeiter [32] untersuchten den Tuberkuloseausbruch an einer britischen Schule mittels ELISPOT- (ESAT-6 und CFP-10) und Heaf-Test. Hier betrug die Übereinstimmung $89 \%$ $(\kappa=0,72, p<0,0001)$. Im Gegensatz zum Heaf-Test zeigte der ELISPOT keine signifikante Korrelation mit dem BCG-Impfstatus.

Eine aktuelle Studie von Ferrara u. Mitarb. [22] stellte bei gleichzeitiger Anwendung von QuantiFERON ${ }^{\circledR}$-TB Gold und THT (5 TU Biocine Test PPD, risikostratifizierte cut-offs) bei unselektierten Klinikpatienten in den 205 Fällen, wo für beide Tests ein eindeutiges Ergebnis vorlag, eine Konkordanz von 70,2\% ( $\kappa=0,4$ fest), wobei die Übereinstimmung bei BCG-Geimpften $(n=53)$ mit $41,5 \%(\kappa=0,09)$ statistisch signifikant geringer war als bei NichtGeimpften mit 80,3\% $(\kappa=0,56)$.

Eine koreanische Arbeitsgruppe [33] stellte für eine überwiegend BCG-geimpfte, HIV-negative Studienpopulation (Medizinstudenten, Klinikpersonal, enge bzw. Haushaltskontakte) bei Einteilung in unterschiedliche Risikogruppen für das Vorliegen einer LTBI insgesamt eine schlechte Übereinstimmung $(\kappa=0,16)$ zwischen THT (2 TU RT 23 SSI, risikostratifizierte cut-offs) und QuantiFERON ${ }^{\circledR}$-TB Gold fest, wobei die Übereinstimmung mit zunehmendem Risiko etwas anstieg. Bei 54 Patienten mit aktiver Tuberkulose reagierten $78 \%$ im THT und $81 \%$ im Interferon$\gamma$-Test positiv $(\kappa=0,4)$.
Pai u. Mitarb. [34] dagegen fanden bei einer großen Studie $(n=726)$ in einem ländlichen Gebiet Indiens bei überwiegend BCG-geimpftem Klinikpersonal eine überraschend gute Übereinstimmung von THT ( 1 TU RT23 SSI, cut-off $10 \mathrm{~mm}$ ) und QuantiFERON $^{\circledR}$-TB Gold In-Tube $(81 \% ; \kappa=0,61)$. Die Resultate mit beiden Testmethoden spiegelten dabei die hohe geschätzte Infektionsprävalenz von etwa $40 \%$ gut wider.

\section{Korrelation der IFN- $\gamma$-Tests mit der M. tuberculosis- Exposition}

Fünf der von Pai u. Mitarb. [13] betrachteten 75 IFN- $\gamma$-Studien befassten sich mit der Korrelation zum Ausmaß der Exposition. In der Untersuchung von Ewer und Mitarbeitern [32] wurden in Großbritannien 535 Schüler mit dem ELISPOT- (ESAT-6 und CFP-10) und mit dem Heaf-Test getestet. Unter Berücksichtigung der Nähe (Schulklasse) und Dauer der gemeinsamen Aktivitäten (Stundenpläne) erfolgte eine Unterteilung in vier Expositionsgruppen, wobei die Wahrscheinlichkeit eines positiven Resultates, stratifiziert nach den vier Gruppen sowohl für den IFN- $\gamma$-Test (OR 2,78 (95\% CI 2,22 - 3,48) als auch für den Heaf-Test (OR 2,33; 95\% CI 1,88 - 2,88) mit Zunahme der Expositionswahrscheinlichkeit anstieg. Der ELISPOT-Test korrelierte dabei signifikant besser mit der Nähe $(p=0,03)$ und Dauer der Exposition $(p=0,007)$ zum Indexfall.

Eine ähnliche Studie führten Brock u. Mitarb. [24] an einer dänischen Hochschule durch $(\mathrm{n}=125$, davon 85 nicht BCG-geimpft). Zum Einsatz kam der QuantiFERON ${ }^{\circledR}$-Test (sowohl RD1- als auch PPD-basiert) sowie der THT bei den Nicht-Geimpften (2 TU RT23 SSI, cut-off $10 \mathrm{~mm}$ ). Die IFN- $\gamma$-Testverfahren ließen bei den ungeimpften Kontaktpersonen eine gute Unterscheidung in zwei Expositionsgruppen (hohes und geringes Risiko) zu. Der QuantiFERON-PPD ermöglichte bei den BCG-Geimpften jedoch keine Unterscheidung. Die Übereinstimmung des QuantiFERON-RD1 und des THT bei den ungeimpften Hochrisiko-Personen lag bei 93\% (95\% KI $86-100 \%)$, bei Schülern mit geringerem Risiko bei $95 \%(95 \%$ KI $88-102 \%)$.

Lalvani u. Mitarb. [35] untersuchten an einer Londoner Ambulanz für Umgebungsuntersuchungen mit dem ELISPOT- (ESAT-6 und PPD) und Heaf-Test prospektiv und geblindet 50 Kontaktpersonen zu Patienten mit mikroskopisch offener Tuberkulose. Es wurden vier Expositionskategorien unterschieden. Während der ESAT-6-ELISPOT mit zunehmender Exposition hochpositiv korrelierte (OR 9,0; 95\% KI 2,6-31,6), war die Korrelation beim HeafTest deutlich schwächer (OR 1,9; 95\% KI 1,0-3,5).

Hill u. Mitarb. [36] untersuchten 735 Haushalts-Kontaktpersonen von Sputum-positiven Tuberkulosepatienten in Gambia mit ELISPOT (PPD und ESAT-6/CFP-10) und THT (2 TU RT23 PPD-S, cut-off $10 \mathrm{~mm}$ ) unter Berücksichtigung der Exposition (gemeinsame Schlafstätte sowie durchschnittliche tägliche Dauer des Kontaktes). Drei Prozent der Kontaktpersonen waren HIV-positiv, $45 \%$ hatten eine BCG-Narbe. Der ESAT-6/CFP-10-ELISPOT sowie der THT korrelierten nach Adjustierung nach Alter, Geschlecht und Ethnizität signifikant mit dem Ausmaß der Exposition, wobei dieser Effekt für den THT ausgeprägter war. Erstaunlicherweise nahm der Anteil THT-positiver und ESAT-6/CFP10-ELISPOT-negativer Personen mit steigender Exposition von $11 \%$ auf $32 \%$ zu. Da fast ein Drittel der Personen mit positivem 
ESAT-6/CFP-10-ELISPOT in der Gruppe mit der geringsten Exposition einen negativen THT hatten, schließen die Autoren daraus auf einen Sensitivitätsverlust des THT in dieser Personengruppe und nehmen an, dass die deutliche Zunahme an positivem THT mit wachsender Exposition durch ein Boosting einer unterdrückten Hautreaktion vom verzögerten Typ zustande kommt. Dass ein Teil der Studienpopulation ( $n=56,8 \%$ ), dabei insbesondere Personen mit geringerer Exposition, PPD-ELISPOT-positiv, aber THT-negativ war, führen die Autoren, nicht ganz nachvollziehbar, ursächlich auf einen Sensitivitätsverlust des THT bei möglicher kutaner Anergie durch regelmäßige muköse Exposition zu Umweltmykobakterien zurück.

Richeldi und Mitarbeiter [37] setzten den ELISPOT-Test (PPD sowie ESAT-6 und CFP-10) und den THT (5 TU Biocine PPD, cut-off $5 \mathrm{~mm}$ ) bei der Untersuchung von Kontaktpersonen einer jungen illegalen Einwanderin aus Moldawien ein. Bei dieser Patientin wurde eine Woche nach Entbindung eine offene multiresistente Lungentuberkulose diagnostiziert. Es wurden 11 Wochen nach Kontakt 41 Neugeborene, 42 Mütter und neun erwachsene Besucher getestet. Von den 92 Studienteilnehmern waren lediglich vier THT-positiv, 17 RD1-ELISPOT-positiv und 34 PPD-ELISPOTpositiv. Lediglich zwei Personen waren in allen drei Tests positiv, 52 in allen Tests negativ. Obgleich die Übereinstimmung von THT und RD1-ELISPOT $81,5 \%$ betrug, war dies nicht statistisch signifikant $(\kappa=0,138, p=0,088)$. Der Grad der Übereinstimmung von RD1-ELISPOT und PPD-ELISPOT war gering $(\kappa=0,247, p=0,010)$, ebenso für PPD-ELISPOT und THT ( $\kappa=0,162, p=0,05$ ). Pro zusätzlicher Stunde, in welcher sich die Kontaktpersonen mit der Infektionsquelle im selben Raum befanden, nahm die Wahrscheinlichkeit eines positiven RD1-ELISPOT zu (Zunahme der Odds um 1,05 [95\% KI 1,02 - 1,09, p = 0,003]), wohingegen sich für die wenigen Fälle mit positivem THT keine Korrelation mit der Exposition zeigen ließ.

Eine koreanische Studie von Kang u. Mitarb. [33] fand für eine überwiegend BCG-geimpfte, HIV-negative Studienpopulation bei Einteilung in unterschiedliche Risikogruppen eine signifikant bessere Korrelation des IFN- $\gamma$-Test (QuantiFERON ${ }^{\circledR}$-TB Gold; THT: 2 TU RT 23 SSI, risikostratifizierte cut-offs) mit dem Ausmaß des Infektionsrisikos, obgleich die Positivitätsraten im IFN$\gamma$-Test bei gesunden Medizinstudenten (4\%) und medizinischem Personal mit gelegentlichem Kontakt zu TB-Patienten (10\%) bei einer geschätzten Infektionsprävalenz von 33\% sehr gering ausfielen.

\section{Beeinflussung der IFN- $\boldsymbol{\gamma}$-Tests durch BCG-Impfung}

Alle von Pai angeführten Studien, welche sich mit dieser Fragestellung auseinandersetzten, konnten zeigen, dass die Spezifität RD1-basierter Testverfahren, bei Stratifizierung nach BCG-Impfstatus, im Gegensatz zu den PPD-basierten IFN- $\gamma$-Tests und dem THT bei BCG-Geimpften deutlich höher ist. So fanden Mori u. Mitarb. [25] bei Testung von 213 angenommen nicht-infizierten, gesunden BCG-geimpften Japanern eine Spezifität von 98,1\% (95\% KI 95,3-99,5\%), wohingegen die „Spezifität“ des THT (japanisches Tuberkulin, äquivalent zu 3 TU PPD-S; bei einem cut-off von $10 \mathrm{~mm}$ ) mit $35,4 \%$ sehr gering, wahrscheinlich aufgrund des BCG-Impfstatus, berechnet wurde.
Auch mehrere Kontakt- und Ausbruchsuntersuchungen bestätigen für RD1-IFN- $\gamma$-Tests keine Beeinflussung durch BCG-Impfung (z.B. $[32,35,38])$.

Johnson u. Mitarb. testeten 54 gesunde THT-negative Medizinstudenten vor (10 TU CSL Tuberkulin) und fünf Monate nach BCG-Impfung. Während ein großer Teil der Studenten nach Impfung eine Reaktion im THT zeigte (29 Personen $>5 \mathrm{~mm}$, sieben $>10 \mathrm{~mm}$, einer $>15 \mathrm{~mm}$ ), blieben $97 \%$ der Studienteilnehmer bei einem ESAT-6-basierten QuantiFERON-Test negativ [17].

Dagegen beeinflusste eine stattgehabte BCG-Impfung bei indischem Klinikpersonal den Ausfall des THT-Ergebnisses kaum (jedoch Testung nur mit 1 TU RT23) [34]. Lalvani u. Mitarb. [39] testeten 40 gesunde Briten (37 davon BCG-geimpft) mit einem ELISPOT, wobei keiner auf ESAT-6 und CFP-10 reagierte. 33 hatten jedoch ein positives Resultat auf PPD.

\section{Beeinflussung der IFN- $\boldsymbol{\gamma}$-Tests durch Infektion mit Umweltmykobakterien}

RD1-Antigene sind zwar in den meisten Umweltmykobakterien nicht vorhanden, die Gene, welche diese Antigene kodieren, konnten jedoch bei M. kansasii, M. marinum, M. szulgai, M. flavescens und M. gastrii nachgewiesen werden [40]. Begrenzte Evidenz lässt auch vermuten, dass die Gensequenzen der verwendeten Antigene der RD1-Region auch in M. leprae zu finden sind [41].

Zur Beeinflussung der IFN- $\gamma$-Tests durch Infektion mit Umweltmykobakterien existieren nur wenige Studien. So testeten Lein u. Mitarb. [42] im Rahmen einer Fall-Kontrollstudie Patienten mit nachgewiesener M. avium complex (MAC)-Infektion mit einem IFN- $\gamma$-Test (PPD und ESAT-6) sowie dem THT $(n=$ jeweils 8). THT und ESAT-6-IFN- $\gamma$-Test waren in allen Fällen negativ, der PPD-basierte Test zeigte eine Spezifität von $75 \%$. Rolinck-Werninghaus u. Mitarb. [43] konnten bei M. avium-Infizierten ebenfalls eine $100 \%$ ige Spezifität eines ESAT-6-IFN- $\gamma$-Test zeigen, wohingegen der THT lediglich bei $60 \%$ Spezifität lag. In der Studie von Mori u. Mitarb. [25] waren von fünf Patienten mit kulturell bestätigter MAC-Infektion vier im QuantiFERON ${ }^{\circledR}$-Test (ESAT6/CFP-10) negativ, wobei im Falle des positiven Testresultates (auf CFP-10) eine Koinfektion möglich ist. Die drei Personen mit positiver M. kansasii-Kultur reagierten positiv. Arend u. Mitarb. [40] untersuchten 12 Patienten mit M. marinum- und M. kansasii-Infektionen sowie 18 Personen mit beruflich langjährigen Kontaktmöglichkeiten zu Umweltmykobakterien (Besitzer tropischer Aquarien, Landtierärzte und Blumenzüchter) vergleichend mit ELISA- und ELISPOT-Verfahren unter Verwendung einzelner und kombinierter Antigene. Die Ergebnisse beider Verfahren waren vergleichbar. Bei mit M. marinum- und M. kansasii-Infizierten ergab sich in mehr als $90 \%$ der Fälle eine positive Reaktion nach Stimulation mit PPD, in drei Viertel der Fälle auf ESAT-6und in zwei Dritteln auf CFP-10, wobei der Anteil reagierender Personen und auch das Ausmaß der Reaktion bei M. marinum-Infektion höher waren. Auf die RD1-Kombination (nur mit ELISPOT getestet) reagierte keine der fünf mit $M$. kansasii, jedoch alle mit M. marinum infizierten Personen. Ein relevanter Anteil der beruflich gegenüber Umweltmykobakterien Exponierten reagierte auf PPD, ESAT-6 und - weniger ausgeprägt - auf CFP-10. So zeigten im ELISA isoliert auf ESAT-6 fünf der sieben Aquariumsbesitzer, 
vier der sechs Landtierärzte und drei der fünf Blumenzüchter eine positive Reaktion. Ähnlich fielen die Reaktionen mit ELISPOT gegenüber ESAT-6 aus, wobei auf die RD1-Kombination nur noch insgesamt drei der 18 beruflich Exponierten positiv reagierten.

\section{Beeinflussung der IFN- $\gamma$-Tests durch antituberkulotische Therapie}

Die hierzu durchgeführten Studien sind höchst widersprüchlich. Einige Arbeitsgruppen fanden eine Abnahme der IFN- $\gamma$-Antwort auf ESAT-6 unter Therapie einer behandlungsbedürftigen Tuberkulose $[28,39,44]$, andere Studien wiederum zeigten eine Zunahme der IFN- $\gamma$-Antwort auf ESAT-6 [45-47] oder gleichbleibende Werte [48] (für ELISPOT). Letzteres konnte auch für PPD IFN- $\gamma$-Tests (QuantiFERON ${ }^{\circledR}$ ) gezeigt werden [31,49], wobei Stuart u. Mitarb. dabei auch Personen unter chemopräventiver Therapie beobachteten [49]. Eine südafrikanische Studiengruppe, welche bei Kindern untersuchte, ob eine Verlaufskontrolle der Interferon- $\gamma$-Produktion mittels ELISPOT (PPD; ESAT-6; CFP-10) nach einem Monat als Bestätigung für eine erfolgreiche Therapie gewertet werden kann, musste davon aufgrund ihrer Erfahrungen abraten [50].

Entscheidenden Einfluss auf den Ausfall der Testergebnisse unter antituberkulotischer Therapie scheint jedoch insbesondere die Inkubationszeit zu haben, da bei kurzen Inkubationsdauern (Erfassung von T-Effektorzellen) die Interferon- $\gamma$-Antwort eher ab-, bei längerer Inkubationsdauer (Erfassung auch von T-Erinnerungszellen) aber zunimmt bzw. konstant bleibt [51].

\section{Beeinflussung der IFN- $\gamma$-Tests durch labortechnische Faktoren}

In einer aktuellen Studie von Doherty u. Mitarb. [52] wurden mögliche Faktoren untersucht, welche dafür verantwortlich sein könnten, dass die Testergebnisse im Rahmen einer longitudinalen Multicenterstudie in Äthiopien zwischen den einzelnen teilnehmenden Kliniken auffallend differierten. Sie beobachteten, dass zeitliche Verzögerungen zwischen Blutabnahme und -Prozessierung bei Verwendung des ELISPOT-Verfahrens zu einem deutlichen und reproduzierbaren Sensitivitäts- und auch tendenziell zu einen Spezifitätsverlust führen. Das ELISPOT-Verfahren zeigte jedoch insgesamt eine etwas höhere Sensitivität. Die ELISA-Technik, und damit QuantiFERON ${ }^{\circledR}$, lieferte in Abhängigkeit vom Zeitfaktor robustere Ergebnisse. Auch das Einfrieren und Auftauen von Zellen beeinflusste die Testergebnisse, glich jedoch die durch zeitliche Verzögerung geschilderten Auswirkungen teilweise wieder aus. Da im Rahmen des Gefrier- und Auftauprozesses ein gewisses Ausmaß an Zelltod und metabolische Veränderungen auftreten, bezweifeln die Autoren, ob die gemessenen Werte akkurat die in vivo-Zytokinproduktion zum Zeitpunkt der Blutentnahme widerspiegeln.

\section{Reproduzierbarkeit der IFN- $\gamma$-Tests}

In drei von vier der in der Arbeit von Pai evaluierten Studien $[14,31,53,54]$ konnte ein hohes Maß an Reproduzierbarkeit gezeigt werden [14,31,53]. Bellete [54] fand, jedoch bei einer kleinen Studienpopulation von elf Fällen, die Reproduzierbarkeit des PPD-IFN- $\gamma$ unzureichend. Diese Studie hat die Frage aufgeworfen, ob der vorausgegangene THT prinzipiell die IFN- $\gamma$-Antwort bei wiederholter Testung im Sinne eines Boosting beeinflussen kann $[55,56]$. Untersucht wurden darüber hinaus für den PPDQuantiFERON ${ }^{\circledR}$-TB-Test die Reproduzierbarkeit bei verschiedenen Test-Orten mit einer Übereinstimmung von mehr als $98 \%$ [14] sowie die Auswirkung der Inkubationszeiten bei Anwendung des ELISA-Verfahrens $(72 \mathrm{~h}$ Vollblut ELISA versus über Nacht-Inkubation mit ELISPOT) mit guter Korrelation der IFN$\gamma$-Antworten auf ESAT-6 und CFP-10 $(r=0,69, p<0,0001)$ [57].

\section{Prädiktive Vorhersagewerte der IFN- $\boldsymbol{\gamma}$-Tests}

Pai u. Mitarb. [13] beschreiben lediglich eine Langzeitstudie [58], aus der die Autoren schließen, dass ein positiver ESAT-6-IFN$\gamma$-Test mit der späteren Entwicklung einer behandlungsbedürftigen Tuberkulose korreliert. Dabei wurden in Äthiopien 24 gesunde, HIV-negative Personen mit einem ESAT-6-IFN- $\gamma$-Test (ELISA) und einem PPD-IFN- $\gamma$-Test nach Haushaltskontakt zu infektiösen Tuberkulosepatienten getestet und nach zwei Jahren nachuntersucht. Insgesamt sieben der untersuchten Personen (29\%) entwickelten in diesem Zeitraum eine behandlungsbedürftige Tuberkulose. Alle sieben waren im ersten PPD-IFN- $\gamma$-Test positiv gewesen, so aber auch weitere 14 der verbleibenden 17 gesunden Personen (83\%). Im Vergleich dazu hatten sechs der sieben Erkrankten initial einen hochpositiven ESAT-6-IFN- $\gamma$-Test (86\%), jedoch nur drei der 17 Nicht-Erkrankten (18\%).

\section{Zusammenfassende Beurteilung der Studienlage}

Basierend auf dem systematischen Review von Pai u. Mitarb. [13] und aktuelleren Studiendaten zeigt sich hinsichtlich der Sensitivität und Spezifität der IFN- $\gamma$-Tests eine große Variabilität, was sich unter anderem in der Inhomogenität der Studienansätze begründet. Im Vergleich zu IFN- $\gamma$-Tests erzielt der THT in den meisten Studien eine etwas höhere Sensitivität. Die Verwendung von RD1-Antigen-Kombinationen führt jedoch zu einer gesteigerten Sensitivität im Vergleich zu PPD-basierten Tests und solchen, die nur mit isolierten Antigenen arbeiten. Während PPD-basierte Tests sehr sensitiv, dafür aber weniger spezifisch sind, erreichen Tests mit isolierten Antigenen gute Spezifitätswerte bei jedoch verhältnismäßig geringer Sensitivität. Die kombinierten RD1-Tests (ESAT-6 + CFP-10) zeigen das günstigste Sensitivitäts-/ Spezifitätsverhältnis. Bei aufgrund positivem THT vermuteter LTBI erreichen die IFN- $\gamma$-Tests eine Sensitivität von etwa $80 \%$.

Hinsichtlich der Korrelation mit dem Ausmaß der Exposition scheinen RD1-IFN- $\gamma$-Tests dem THT überlegen zu sein.

Besonders vorteilhaft scheint die Anwendung der RD1-kombinierten IFN- $\gamma$-Tests bei BCG-geimpften Personen zu sein, da hier im Vergleich zu allen anderen Testmethoden die Spezifität besonders hoch ist.

Bezüglich der Beeinflussung durch Infektionen mit Umweltmykobakterien ist die Datenlage noch sehr unbefriedigend, offensichtlich ist die T-Zellantwort auf ESAT-6 und CFP-10 nicht völlig spezifisch für eine M. tuberculosis-Komplex-Infektion und kann durch manche Infektionen mit Umweltmykobakterien beeinflusst sein. Es ist aber aufgrund der Verwendung spezifischerer Antigene bei den RD1-IFN- $\gamma$-Tests eine geringere Kreuzreaktogenität, insbesondere im Vergleich zum THT, anzunehmen.

Auch zur Wahrscheinlichkeit der Progression in eine behandlungsbedürftige Tuberkulose bei positivem IFN- $\gamma$-Test fehlt es 
an ausreichenden Daten, in der bisher einzigen Studie wird ein Zusammenhang angenommen.

Die wenigen Studien zur Reproduzierbarkeit deuten auf eine akzeptable Zuverlässigkeit der Testverfahren hin [16], wobei sich die Datenlage weitgehend auf ältere Testgenerationen beschränkt.

Die spärlichen Daten zur Auswirkung von chemotherapeutischen Interventionen auf das IFN- $\gamma$-Testresultat sind dagegen widersprüchlich und lassen keine abschließende Aussage zu.

Vergleichende Studien mit der ELISA- und ELISPOT-Technik gibt es wenige [57] bzw. die Ergebnisse aus solchen Untersuchungen wurden nicht oder nur partiell publiziert (z.B. [37]). Tab. 2 stellt die Charakteristika der beiden eingangs beschriebenen Testverfahren einander gegenüber. Vorteile des ELISPOT-Tests sind seine möglicherweise etwas höhere Sensitivität [57] und die Tatsache, dass die Lymphozytenzahl berücksichtigt wird. Vorteilhaft an der ELISA-Technik sind die weniger stringenten Zeitgrenzen, der geringere Zeitaufwand bei der Durchführung, sowie die - zumindest theoretisch - vergleichsweise geringeren Kosten. Tab. 3 gibt eine zusammenfassende Übersicht über die Vor- und Nachteile der IFN- $\gamma$-Tests.

\section{Limitationen und offene Fragestellungen}

Ein grundsätzlicher Kritikpunkt an den Daten zu den IFN- $\gamma$-Tests ist, dass die Bestimmung der Sensitivität bei behandlungsbedürftiger Tuberkulose möglicherweise wenig Rückschlüsse über die Aussagekraft der neuen Testverfahren bei LTBI zulässt. Es muss bezweifelt werden, ob eine aktive Tuberkulose als Modell einer LTBI geeignet ist. Bei der Beurteilung der Sensitivität bezüglich der Detektion einer LTBI ist es problematisch, dass mit dem THT kein optimaler „Goldstandard“ als Referenzmethode zur Verfügung steht. Daraus ergibt sich die Frage, in wie weit das Ausmaß der Korrelation von IFN- $\gamma$-Tests und THT, welches je nach Studie deutlich variiert, tatsächlich von Bedeutung ist.

Optimal wäre die Überprüfung der Sensitivität anhand der Untersuchung von frischen, BCG-ungeimpften THT-Konvertoren. Aber selbst dann wäre eine zuverlässige Aussage, ob die Sensitivität der neuen Testverfahren die des THT tatsächlich übertrifft, noch nicht möglich. Dies würde erst ein Studienansatz klären, welcher THT-negative, aber IFN- $\gamma$-Test-positive Kontaktpersonen über einen langen Zeitraum nachbeobachtet und die Erkrankungsraten mit denen einer THT-positiven Kontrollgruppe vergleicht. Dann würde sich zeigen lassen, ob es sich bei den THTnegativen, aber IFN- $\gamma$-Test-positiven Personen tatsächlich um eine LTBI oder lediglich um den Nachweis einer transienten Infektion bzw. Antigenexposition gehandelt hat. Beide Gruppen dürften keiner Behandlung unterzogen werden, was ethisch zweifelhaft sein kann (z.B. bei immunsupprimierten Patienten vor Organtransplantationen). Zum anderen ist die Durchführung solcher Studien in Ländern, welche bei LTBI routinemäßig eine Chemoprävention empfehlen, kaum machbar [59]. Erforderlich ist auch die langfristige Nachbeobachtung der IFN- $\gamma$-Test-negativen Testpersonen, um zuverlässig die Häufigkeit falsch-negativ Getesteter und die zugrundeliegenden Faktoren zu erfassen.

Tab. 2 Gegenüberstellung QuantiFERON ${ }^{\circledR}$-TB Gold In-Tube und T Spot-TB-Test

QuantiFERON ${ }^{\circledR}$-TB T Spot-TB

Gold In-Tube

\begin{tabular}{|c|c|c|}
\hline \multicolumn{3}{|l|}{ Hersteller/Homepage } \\
\hline Testmedium & Vollblut & $\begin{array}{l}\text { periphere mononukleäre } \\
\text { Zellen }\end{array}$ \\
\hline Antigene & $\begin{array}{l}\text { ESAT6, CFP10, } \\
\text { Tb } 7.7\end{array}$ & ESAT6, CFP10 \\
\hline Messmethode & ELISA & ELISPOT \\
\hline gemessene Zielgröße & IFN- $\gamma$ & IFN- $\boldsymbol{\gamma}$ produzierende T-Zellen \\
\hline benötigtes Blutvolumen & $2 \mathrm{ml}$ & mind. $8 \mathrm{ml}$ (Erwachsene) \\
\hline Testanzahl pro Kit & $\max .88$ & $\max .24$ \\
\hline $\begin{array}{l}\text { Zeitfenster nach Blutent- } \\
\text { nahme bis zur Weiterver- } \\
\text { arbeitung im Labor }\end{array}$ & $\begin{array}{l}\text { innerhalb von } \\
\text { max. } 16 \text { Stunden }\end{array}$ & $\begin{array}{l}\text { schnellstmöglich, direkt vor } \\
\text { dem Testansatz zentrifugieren, } \\
\text { möglichst innerhalb von zwei } \\
\text { Stunden nach Blutentnahme }\end{array}$ \\
\hline
\end{tabular}

Tab. 3 Vor- und Nachteile der IFN- $\boldsymbol{\gamma}$-Tests

\begin{tabular}{|c|c|}
\hline Vorteile [mod. nach [21]] & Nachteile \\
\hline $\begin{array}{l}\text { - keine Wiedervorstellung zur Test- } \\
\text { ablesung }\end{array}$ & $\begin{array}{l}\text { - venöse Blutabnahme, ggf. mit spe- } \\
\text { ziellem Abnahmesystem }\end{array}$ \\
\hline $\begin{array}{l}\text { - Reduktion des Arbeitsaufwandes } \\
\text { (für den Untersucher) }\end{array}$ & $\begin{array}{l}\text { - Verfügbarkeit eines qualifizierten } \\
\text { Labors }\end{array}$ \\
\hline $\begin{array}{l}\text { - schnelle Verfügbarkeit des Tester- } \\
\text { gebnisses }\end{array}$ & - Arbeitsaufwand für Laboratorien \\
\hline $\begin{array}{l}\text { - geringere Anfälligkeit für Ablese- } \\
\text { bias und -fehler }\end{array}$ & $\begin{array}{l}\text { - zeitliche Limitationen bei Weiter- } \\
\text { verarbeitung der Blutprobe }\end{array}$ \\
\hline - „einfache“ ja/nein-Antwort & $\begin{array}{l}\text { - Transportlogistik (Temperatur, } \\
\text { Lagerung) }\end{array}$ \\
\hline $\begin{array}{l}\text { - kein Confounding durch BCG und } \\
\text { die meisten Umweltmykobakte- } \\
\text { rien }\end{array}$ & - deutlich höhere Kosten als THT \\
\hline $\begin{array}{l}\text { - möglicherweise geringere Beein- } \\
\text { flussung durch Immunsuppression } \\
\text { u./o. schwere Begleiterkrankun- } \\
\text { gen }\end{array}$ & $\begin{array}{l}\text { - mögliche Beeinflussung des Tester- } \\
\text { gebnisses durch antituberkuloti- } \\
\text { sche Therapie }\end{array}$ \\
\hline $\begin{array}{l}\text { - keine Booster-Reaktionen bei wie- } \\
\text { derholten Testungen (z. B. bei Be- } \\
\text { schäftigten im Gesundheitswesen) }\end{array}$ & $\begin{array}{l}\text { - ungeklärte Duldungspflicht bei } \\
\text { Untersuchungen nach Infektions- } \\
\text { schutzgesetz }\end{array}$ \\
\hline $\begin{array}{l}\text { - langfristig günstige Kostenrelati- } \\
\text { on, da keine Therapie/Kontrolle } \\
\text { falsch-positiver Reagenten }\end{array}$ & $\begin{array}{l}\text { - ungeklärte Kostenübernahme } \\
\text { durch die Krankenkassen und an- } \\
\text { dere Kostenträger z.Zt. noch unbe- } \\
\text { friedigende Datenlage zu entschei- } \\
\text { denden Fragestellungen }\end{array}$ \\
\hline $\begin{array}{l}\text { - erleichtertes Screening größerer } \\
\text { Personenzahlen (z. B. Ausbrüche) }\end{array}$ & \\
\hline
\end{tabular}

Durch die bisher veröffentlichten Studien wird auch die Möglichkeit eines „Boosting“ der IFN- $\gamma$-Tests durch zwischenzeitlich erfolgte Tuberkulinhauttestungen nicht ausreichend thematisiert. Hill und Mitarbeiter [36] gehen zudem davon aus, dass die Verwendung von zwei Antigenen für eine zuverlässige Diagnose der LTBI nicht ausreichend ist.

Neben der Bedeutung der neuen Testverfahren zur Detektion einer LTBI sollte ihr Stellenwert in der Diagnostik der behandlungsbedürftigen Tuberkulose durchaus auch angesprochen 
werden. Insbesondere im Sinne einer Ausschlussdiagnostik wäre ein Testverfahren, welches dem THT überlegen ist, von großem Interesse, so beispielsweise bei BCG-geimpften Migranten aus Hochprävalenzländern mit pathologischen Veränderungen im Röntgen-Thorax. Da es sich bei den in Studien untersuchten Patientengruppen in der Regel um bakteriologisch bestätigte und damit überwiegend um pulmonale Tuberkulosen handelt, sind die Erfahrungen mit extrapulmonalen Tuberkuloseformen beschränkt.

Der Effekt von durch Umweltmykobakterien bedingten Mykobakteriosen auf die Aussagekraft der IFN- $\gamma$-Testverfahren kann nicht abschließend beurteilt werden, da die untersuchten Fallzahlen klein sind [42,45]. Barnes [59] äußert die Vermutung, dass einige Organismen über RD1-verwandte Gene verfügen und damit eine Kreuzreaktivität gegenüber RD1-Antigenen nicht ausgeschlossen werden kann [60,61]. Die Prävalenz von Umweltmykobakterien kann lokal stark variieren [62], wobei die epidemiologische Datenlage, insbesondere auch für Deutschland, nicht befriedigend ist. Infektionen mit $M$. kansasii sind beispielsweise im Südwesten der USA häufig und könnten dort durchaus zu einem relevanten Anteil falsch-positiver Testresultate führen [59]. Kleinere Studien lassen vermuten, dass bei Personen mit durch M. avium-Komplex verursachten Lungenerkrankungen die IFN- $\gamma$-Tests negativ ausfallen [42], Daten für gesunde, mit M. avium-Komplex lediglich infizierte Personen (und geringem LTBI-Risiko) existieren, wie auch für andere durch Umweltmykobakterien bedingte Mykobakteriosen, jedoch nicht [59].

Die Verfahren sind gerade für die Personengruppen, bei denen eine zuverlässigere Alternative zum Tuberkulinhauttest dringend gefordert wird, nicht bzw. unzureichend klinisch getestet (s. Tab.4). So wurde die Aussagekraft der Tests beispielsweise bei medikamentös induzierter Immunsuppression nicht systematisch untersucht, die bisherigen - positiven - Erfahrungen basieren auf Einzelfallberichten für je einen Patienten mit Morbus Crohn [63] und Dermatomyositis [26].

Ferrara u. Mitarb. [22] haben erstmals einen Interferon- $\gamma$-Test im Vergleich mit dem THT bei einem unselektierten Patientengut $\left(\mathrm{n}=318\right.$ ) eingesetzt und verglichen (QuantiFERON ${ }^{\circledR}$-TB Gold versus Biocine Test PPD). Bei etwas mehr als der Hälfte der Patienten wurde der Test aufgrund eines Verdachts auf behandlungsbe-

Tab. 4 IFN- $\gamma$-Tests: Personengruppen/Indikationen, für welche nur mangelnde bzw. keine Anwendungsdaten vorliegen

\footnotetext{
- im Neugeborenen-, Kindes- und Jugendalter

- bei Schwangeren

- bei Begleiterkrankungen mit Beeinflussung der IFN- $\gamma$-Produktion

(z. B. Influenza, Sarkoidose)

- bei geschlossenen und extrapulmonalen Tuberkulosen

- für unterschiedliche Schweregrade der Tuberkulose

- bei Vorliegen unterschiedlicher genetischer Faktoren (z. B. HLA-Zugehörigkeit, Ethnizität)

- bei Immunsupprimierten (HIV, iatrogen Supprimierte, Organtransplantierte)

- bei im Gesundheitsdienst Tätigen (arbeitsmedizinische/betriebsärztliche Untersuchungen)
}

dürftige Tuberkulose angeordnet, 65 (20,4\%) erhielten zurzeit der Testung eine immunsuppressive Therapie (39 zytostatische Chemotherapie, 31 systemische Kortikosteroide [darunter acht der Tumorpatienten], drei anti-TNF- $\alpha$-Behandlung). Die IFN$\gamma$-Testresultate wurden als positiv, negativ und "nicht eindeutig“ („,indeterminate“) definiert. „Nicht eindeutige“ Resultate ergaben sich signifikant häufiger bei Personen mit negativem THT ( $28,9 \%$ vs. $6,6 \%$ bei THT-positiven Patienten) und waren signifikant häufiger bei immunsuppressiv behandelten Patienten (OR $3,35,95 \%$ KI 1,84-6,08). Die Autoren schlussfolgern, dass die in vitro-Testung möglicherweise, ähnlich wie der THT, bei immunsuppressiv behandelten Patienten nur eingeschränkten klinischen Nutzen hat.

Auch die Auswirkung des HIV-Status ist nicht ausreichend evaluiert. Während Chapman u. Mitarb. [27] auch für HIV-positive TBPatienten eine gute Sensitivität bestimmten $(\mathrm{n}=11)$, fanden Elliot u. Mitarb. [64] die IFN- $\gamma$ Antwort auf PPD und CFP bei HIVPositiven $(n=22)$ im Vergleich zu HIV-Negativen $(=75)$ deutlich eingeschränkt $(p \leq 0,001)$.

Hill u. Mitarb. [36] fordern zu Recht weitere Untersuchungen an Personen aus Hochendemiegebieten. Unter den von dieser Arbeitsgruppe getesteten 735 Kontaktpersonen in Gambia (ELISPOT PPD und ESAT-6/CFP-10) waren erstaunlicherweise 35\% der untersuchten Personen ELISPOT-negativ. Die Autoren vermuten, dass die in vitro-Reaktion nach Infektion über die Zeit abnimmt, zumal die Testverfahren der neueren Generation mit kurzen Inkubationszeiten wahrscheinlich nur die IFN- $\gamma$-Produktion von T-Effektorzellen und nicht von Gedächtniszellen berücksichtigen. Dies wirft die Frage auf, ob sich die IFN- $\gamma$-Tests prinzipiell nur zur Detektion relativ „frischer“ Infektionen eignen oder ob auch jahrzehntelang zurückliegende Infektionen erfasst werden. Auch die koreanische Arbeitsgruppe von Kang [33] vermutet aufgrund geringer Positivitätsraten im Interferon$\gamma$-Test bei gesunden Testpersonen ( $4-10 \%$ ), aber lokal insgesamt deutlich höher geschätzter Infektionsprävalenz (33\%), dass in vitro-Tests der neueren Generation eher frische als ältere Infektionen erkennen können.

Obgleich in der Studie von Pai [34] THT und QuantiFERON ${ }^{\circledR}-\mathrm{TB}$ Gold In-Tube-Ergebnisse bei indischem Klinikpersonal sehr gut korrelierten $(\kappa=0,6)$, fand sich die Kombination von positivem Haut- und negativem IFN- $\gamma$-Test etwas häufiger - allerdings nicht statistisch signifikant - mit zunehmendem Alter, bei längerer Beschäftigungsdauer und in speziellen Berufsgruppen. Auch dies könnte darauf hinweisen, dass ältere Infektionen möglicherweise nicht erfasst werden. Dagegen ergab eine Studie von Lalvani u. Mitarb. [39] an gesunden Einwohnern Bombays $(n=100)$ bei Verwendung eines ELISPOT (ESAT-6 und CFP-10), dass 80\% der untersuchten Personen mindestens auf eines der Antigene reagierten, worin die Autoren die angenommene hohe Infektionsprävalenz als bestätigt sehen.

Unzureichend ist noch die bisherige Datenlage bei Kindern. Im Dezember 2004 wurde die erste große prospektive Studie an Kleinkindern (mittleres Alter 3 Jahre) aus Südafrika veröffentlicht [65]. In unterschiedlichen Gruppen Tuberkulose-kranker Kinder (HIV positiv, unterernährt, < 3 Jahre) war die Sensitivität eines ELISPOT (verwendete Antigene: rekombinantes ESAT-6, 
ESAT-6 und CFP-10) dem THT (2 TU RT 23 PPD-S) deutlich überlegen (siehe Tab. 5).

Eine weitere Studie aus Südafrika [50] setzte ebenfalls einen ELISPOT-Test (PPD; ESAT-6; CFP-10) bei 70 HIV-negativen Kindern mit klinischer Tuberkulosediagnose (davon letztendlich 12 kulturell bestätigt) sowie bei 26 Kindern mit Kontakt zu einem infektiösen Tuberkulosepatienten ein. Je wahrscheinlicher eine behandlungsbedürftige Tuberkulose vorlag, desto höher war die Positivitätsrate der RD-1 basierten Tests ( $83,3 \%$ bei bestätigter Tuberkulose, 72,3\% bei klinisch sehr wahrscheinlicher und 45,5\% bei klinisch wahrscheinlicher Tuberkulose). Wiederholte Messungen der Interferon- $\gamma$-Produktion unter Therapie, um bei nicht gesicherter Diagnose diese zu bestätigen bzw. zu entkräften, könnten nach Einschätzung der Autoren möglicherweise hilfreich sein, konnten aber aufgrund der eigenen Erfahrungen nicht empfohlen werden. So konnte eine Beeinflussung der Testresultate durch den initial angelegten THT (2 TU RT23 SSI) nicht ausgeschlossen werden, so dass hier weitere Studien notwendig sind, um die Aussagekraft von Verlaufskontrollen richtig einordnen zu können. Bei den gesunden Kontaktpersonen korrelierten die RD1-basierten IFN- $\gamma$-Tests gut mit dem THT.

Richeldi u. Mitarb. [37] heben in ihrer Studie hervor, dass von 41 exponierten Neugeborenen keines auf den THT bzw. den PPDELISPOT, zwei jedoch im RD1 ELISPOT-Test reagierten. Die Autoren führen aus, dass aufgrund der eingeschränkten Immunreaktion vom verzögerten Typ Reaktionen auf PPD oftmals falsch negativ ausfallen, der RD1-ELISPOT aber eine LTBI-Diagnose ermöglichen kann. Alle 41 Kinder reagierten in der Positiv-Kontrolle, die Reaktion fiel jedoch signifikant schwächer aus als bei den Erwachsenen ( $p>0,0001)$. Das Kind der erkrankten Mutter wurde sieben Wochen nach Beginn einer chemopräventiven Therapie mit Ethambutol und Pyrazinamid (insgesamt über 9 Monate) mit allen drei Tests negativ getestet, entwickelte aber dennoch knapp 24 Monate nach Exposition eine behandlungsbedürftige, bakteriologisch gesicherte multiresistente Tuberkulose. Bei Ver-

Tab. 5 Effekt von Alter, HIV-Infektion und Unterernährung auf die Sensitivität des ELISPOT (ESAT-6 und CFP-10) und THT (2 TU RT 23 PPD-S) bei südafrikanischen Kindern [65]. Prospektive Kohortenstudie: $n=293(B C G+)$ mit Verdacht auf Tuberkulose, $30 \mathrm{HIV+}$, durchschnittliches Alter 3 Jahre (18-72 Monate), keine Therapie oder $<4$ Wo., follow-up 6 Monate [65]

\begin{tabular}{llll}
\hline Sensitivität & $\begin{array}{l}\text { ELISPOT-positiv } \\
\text { (95\% KI) }\end{array}$ & $\begin{array}{l}\text { THT positiv } \\
\text { (> 15 mm, bei } \\
\text { HIV+ jegliche } \\
\text { Induration) }\end{array}$ & p-Wert \\
\hline $\begin{array}{l}\text { bakteriologisch bestätigte } \\
\text { Tuberkulosen (n=57) }\end{array}$ & $81 \%(68-90)$ & $35 \%(21-51)$ & $<0,0001$ \\
\hline $\begin{array}{l}\text { bestätigte bzw. hochwahr- } \\
\text { scheinliche Tuberkulosen } \\
\text { (n=133) }\end{array}$ & $83 \%(75-89)$ & $63 \%(54-72)$ & 0,0004 \\
\hline$<3$ Jahre & $85 \%(73-93)$ & $51 \%(37-65)$ & 0,001 \\
\hline $\begin{array}{l}\text { HIV-Koinfektion } \\
\text { Malnutrition }\end{array}$ & $73 \%(54-88)$ & $36 \%(18-58)$ & 0,005 \\
\hline
\end{tabular}

*kombinierte Sensitivität für Fälle, in denen sowohl mit ELISPOT und THT getestet wurde $(n=116): 91 \%(85-96)$ laufskontrollen vor Erkrankungsbeginn (3, 6, 12, 18 und 24 Monate nach Exposition) reagierte der ELISPOT-Test nach 6 Monaten, eine THT-Konversion wurde erst kurz vor Einsetzen klinischer Symptome festgestellt [Präsentation Dr. Richeldi, IUATLDKongress Paris, 31.10.2004].

Die Frage, wie sich eine therapeutische Intervention auf den Teststatus auswirkt, ist gerade im Kindesalter von entscheidender Bedeutung. Bisher gilt die Empfehlung, exponierte Kleinkinder bei negativem THT chemoprophylaktisch zu behandeln. Nach drei Monaten wird das weitere Prozedere vom Ausfall des Kontrolltests abhängig gemacht: bei positivem THT wird, nach Ausschluss einer Organtuberkulose, im Sinne einer Chemoprävention für weitere sechs Monate weiterbehandelt, bei negativem Ausfall ist keine Infektion erfolgt bzw. wurde verhindert, damit kann die Behandlung eingestellt werden. Unter Berücksichtigung der bisher verfügbaren Daten wäre bei Einsatz eines IFN$\gamma$-Tests nach drei Monaten chemopräventiver Therapie möglicherweise ein negativer Testausfall zu erwarten, selbst wenn es tatsächlich zu einer Infektion kam. Ob dieses negative Ergebnis den Rückschluss zulässt, dass keine lebensfähigen Erreger mehr vorhanden sind und damit eine Fortführung der Therapie nicht mehr notwendig ist, kann zum jetzigen Zeitpunkt nicht beantwortet werden.

Unklar ist bislang auch, in welchem Zeitfenster mit einer IFN$\gamma$-Test-,Konversion“ zu rechnen ist. Vermutet wird zwar im Vergleich zum THT eine schnellere Reaktion, die Angaben der Hersteller richten sich jedoch bislang nach den Erfahrungen mit dem THT, welcher in der Regel 6-8 Wochen nach Infektion umschlägt.

Letztendlich sind auch technische Detailfragen noch nicht oder nur unbefriedigend untersucht, so beispielsweise der Einfluss von Lagerung, Temperatur (Tiefkühlung), Inkubationszeiten und Art der Blutabnahme auf die Testergebnisse.

Hill u. Mitarb. [36] hinterfragen zudem die empfohlenen cutoffs, da nach ihrer Einschätzung nicht einmal die eigene, verhältnismäßig große Studie ausreichend Daten für eine Sensitivitätsanalyse des gewählten cut-offs liefern konnte.

$\mathrm{Zu}$ bemängeln ist zudem, dass bisher vergleichsweise wenige Studien tatsächlich mit den eingangs vorgestellten Testverfahren, insbesondere mit dem QuantiFERON ${ }^{\circledR}$-TB Gold In-Tube, durchgeführt wurden.

Grundsätzlich problematisch ist, dass zur Beantwortung vieler offener Fragestellungen organisations- und kostenaufwändige Studienansätze notwendig wären.

Fazit

Basierend auf der derzeitigen Datenlage haben die Interferon$\gamma$-Tests, welche eine Kombination aus RD1-Antigenen verwenden, durchaus das Potenzial, sich als zusätzliches diagnostisches Mittel zu etablieren. Sie verfügen im Vergleich zum Tuberkulinhauttest über eine größere Spezifität, keine bzw. eine geringere Kreuzreaktivität mit BCG und Umweltmykobakterien und schei- 
nen besser mit dem Expositionsgrad zu korrelieren. Weitere Vorteile sind die einmalige Vorstellung der Testperson, die geringere Anfälligkeit für Ablesefehler sowie die mögliche schnelle Verfügbarkeit des Testergebnisses. Eindeutige Nachteile sind die Notwendigkeit eines erfahrenen Labors und der logistischen Rahmenbedingungen (Transport, Einhaltung der Zeitlimits) sowie die deutlich höheren Kosten, insbesondere bei Einzelbestimmung (Tab. 3).

Um den Wert dieser Verfahren und ihre konkreten Indikationsbereiche sicher beurteilen zu können, müssen noch wichtige wissenschaftliche Fragestellungen beantwortet werden (s. Tab.4). So muss sich das Verfahren (und im Besonderen die in Deutschland nun erhältlichen Tests) beispielsweise in den Personengruppen, bei denen ein solches diagnostisches Mittel am dringendsten benötigt wird, wie beispielsweise bei Kindern, Schwangeren, immunsupprimierten Patienten, extrapulmonalen Tuberkulosen und Migranten aus Hochprävalenzländern, erst bewähren. Hierzu, ebenso wie zur Bestimmung des positiven prädiktiven Werts der IFN- $\gamma$-Tests, sind weitere, gut geplante Langzeitstudien notwendig. Auch Fragestellungen wie Praktikabilität und Kosten/Nutzenrelation müssen berücksichtigt werden.

Insbesondere auch Erkenntnisse aus in Deutschland derzeit laufenden Studien können wesentlich dazu beitragen, die angesprochenen Wissensdefizite zu verkleinern und genaue Anwendungsbereiche zu definieren. Aktuelle Beispiele hierfür sind der Einsatz von IFN- $\gamma$-Tests im Rahmen von Umgebungsuntersuchungen im Gesundheitsamt Hamburg [persönl. Kommunikation PD Dr. R. Diel], bei Kindern [persönl. Kommunikation Dr. K. Magdorf] sowie eine Anwendungsbeobachtung zum Screening bei Bundeswehrsoldaten mit Auslandseinsatz [persönl. Kommunikation Dr. I. Niebel].

Unter Berücksichtigung des derzeitigen Kenntnisstandes lassen sich nach unserer Einschätzung die in Tab. $\mathbf{6}$ aufgeführten möglichen Anwendungsbereiche ableiten. Es muss jedoch nochmals betont werden, dass die Datenlage für die meisten der dort angeführten Zielgruppen bisher nicht ausreichend gesichert ist und dass Ergebnisse des IFN- $\gamma$-Tests nur in Ergänzung zu den herkömmlichen diagnostischen Verfahren bewertet werden sollte.

Der Tuberkulinhauttest mag angesichts seines Alters von weit über 100 Jahren und seiner vielen Schwächen antiquiert und inadäquat erscheinen. Fest steht jedoch, dass uns diese Schwächen sehr genau bekannt sind und wir über 100 Jahre Zeit hatten, um

Tab. 6 Mögliche Indikationen für IFN- $\gamma$-Teste (in Ergänzung zu herkömmlichen diagnostischen Verfahren)

- akut lebensbedrohliche Tuberkuloseformen (z. B. Meningitis tuberculosa)

- Verdacht auf Tuberkulose bei Anergie (z. B. Immunsuppression) oder Hypergie (BCG-Impfung)

- vor Organtransplantationen

- vor Einsatz von Biologicals (z. B. anti-TNF- $\alpha$-Therapie)

Tuberkulose-exponierte Neugeborene

für alle gilt: es existieren noch keine ausreichend gesicherten Daten
Erfahrungen damit zu sammeln. Ein kompletter Ersatz des Tuberkulinhauttests durch die beschriebenen immunologischen Verfahren wäre mit Sicherheit verfrüht. Als ergänzendes diagnostisches Verfahren bei bestimmten klinischen Fragestellungen könnten sie sich jedoch durchaus als nützlich erweisen.

Glossar

BCG Bacillus Calmette-Guérin

CFP-10 culture filtrate protein 10

ELISA Enzyme-Linked Immunosorbent Assay

ELISPOT Enzyme-Linked Immunospot Assay

ESAT-6 Early secreted antigenic target $6 \mathrm{kDa}$

Heaf-Test Multipunkturmethode, mit der unter Verwendung eines speziellen Applikators Tuberkulin in die Haut eingebracht wird

IFN- $\gamma \quad$ Interferon-gamma

INH Isoniazid

KI Konfidenzintervall (i.d.R. 95\%)

OR Odds Ratio

LTBI latente tuberkulöse Infektion

PBMC peripheral blood mononuclear cells

PPD purified protein derivative

RD1 region of difference 1

TB Tuberkulose

THT Tuberkulinhauttest

\section{Danksagung}

Das DZK bedankt sich für die finanzielle Unterstützung durch das Bundesministerium für Gesundheit und Soziale Sicherung, die auch diese Publikation ermöglicht hat. Unser Dank gilt Frau Birgit Howe, welche uns hinsichtlich der Darstellung der Testabläufe beraten hat, Frau Anja Hedrich für die redaktionelle Textbearbeitung sowie den Herstellerfirmen Cellestis und Oxford Immunotec für die Information und freundliche Kooperation.

\section{Literatur}

${ }^{1}$ Comstock GW, Livesay VT, Woolpert SF. The prognosis of a positive tuberculin reaction in childhood and adolescence. Am J Epidemiol 1974; 99: $131-138$

2 Vynnycky E, Fine PEM. Life time risks, incubation period, and serial interval of tuberculosis. Am J Epidemiol 2000; 152: 247-263

${ }^{3}$ American Thoracic Society, Prevention. CfDCa. Targeted tuberculin testing and treatment of latent tuberculosis infection. Am J Respir Crit Care Med 2000; 161 (Suppl): S221 - S247

${ }^{4}$ Schaberg T, Hauer B, Haas W et al. Latente tuberkulöse Infektion: Empfehlungen zur präventiven Therapie bei Erwachsenen in Deutschland. Pneumologie 2004; 58: 255-270

${ }^{5}$ Loddenkemper R. Editorial zu „Theoretische und praktische Überlegungen bei Anwendung des Tuberkulintests“. Pneumologie 1997; 51: $1023-1024$

${ }^{6}$ Rieder HL. Theoretische und praktische Überlegungen bei Anwendung des Tuberkulintests. Pneumologie 1997; 51: 1025-1032

${ }^{7}$ Sagebiel D, Hauer B, Haas W et al. Zukünftige Tuberkulinversorgung in Deutschland. Bundesgesundheitsbl-Gesundheitsforsch-Gesundheitsschutz 2005; 48: 477-482

${ }^{8}$ Andersen P, Munk ME, Pollock JM et al. Specific immune-based diagnosis of tuberculosis. Lancet 2000; 356: 1099-1104 
${ }^{9}$ Huebner RE, Schein MF, Bass JB Jr. The tuberculin skin test. Clin Infect Dis 1993; 17: $968-975$

${ }^{10}$ Hirtl T. Das Tuberkulin. Schriftenreihe Gesund in Wien. Wien: Literas Universitätsverlag, 2000

${ }^{11}$ NICE Guideline. Tuberculosis: clinical diagnosis and management of tuberculosis, and measures for its prevention and control. First draft for consultation. Juni 2005

${ }^{12}$ Centers for Disease Control and Prevention. Draft guidelines for preventing the transmission of Mycobacterium tuberculosis in healthcare settings. (http://www.cdc.gov/nchstp/tb/Federal_Register/ default.htm), 2004/2005

${ }^{13}$ Pai M, Riley LW, Colford JM Jr. Interferon- $\gamma$ assays in the immunodiagnosis of tuberculosis: a systematic review. The Lancet Inf Dis 2004; 4: $761-776$

${ }^{14}$ US Food and Drug Administration. QuantiFERON ${ }^{\circledR}-$ TB-P010033 Summary of safety and effectiveness. Rockville, MD: Food and Drug Administration 2002 http//:www.fda.gov/cdrh/pdf/P010033b.pdf, 2004

${ }^{15}$ Mazurek GH, Villarino ME. Guidelines for using the QuantiFERON-TB test for diagnosing latent Mycobacterium tuberculosis infection. MMWR 2003; 52: 15-18

${ }^{16}$ Dheda K, Udwadia ZF, Huggett JF et al. Utility of the antigen-specific interferon- $\gamma$ assay for the management of tuberculosis. Curr Opin Pulm Med 2005; 11: 195-202

${ }^{17}$ Johnson PDR, Stuart RL, Grayson ML et al. Tuberculin-purified protein derivative-, MPT-64-, and ESAT-6-stimulated gamma interferon responses in medical students before and after Mycobacterium bovis BCG vaccination and in patients with tuberculosis. Clin Diagn Lab Immunol 1999; 6: $934-937$

18 Cellestis. QuantiFERON ${ }^{\circledR}$-TB Gold (In-Tube Method). Package Insert. www.cellestis.com,

${ }^{19}$ Katial RK. Immunodiagnostics for Latent Tuberculosis Infection. In: Madkour MM. (Hrsg): Tuberculosis. Springer Verlag, 2003: S. $231-239$

${ }^{20}$ Cellestis. QuantiFERON ${ }^{\circledR}$-TB Gold. Package Insert. www.cellestis.com

${ }^{21}$ Lalvani A. Spotting latent infection: the path to better tuberculosis control. Thorax 2003; 58: 916-918

22 Ferrara G, Losi M, Meacci M et al. Routine hospital use of a new commercial whole blood interferon- $\gamma$ assay for the diagnosis of tuberculosis infection. Am J Crit Care Med 2005; 172: 631-635

${ }^{23}$ Heaf $\mathrm{F}$. The multiple puncture tuberculin test. Lancet 1951; 21: $151-153$

${ }^{24}$ Brock I, Weldingh K, Lillebaek T et al. Comparison of tuberculin skin test and new specific blood test in tuberculosis contacts. Am J Respir Care Med 2004; 170: 65-69

${ }^{25}$ Mori T, Sakatani M, Yamagishi F et al. Specific detection of tuberculosis infection. An interferon- $\gamma$-based assay using new antigens. Am J Respir Crit Care Med 2004; 170: 59-64

${ }^{26}$ Ravn P, Munk ME, Andersen AB et al. Reactivation of tuberculosis during immunosuppressive treatment in a patient with positive QuantiFERON $^{\circledR}$-RD1 Test. Scand Infect Dis 2004; 3 36: 499 - 501

${ }^{27}$ Chapman ALN, Munkanta M, Wilkinson KA et al. Rapid detection of active and latent tuberculosis infection in HIV-positive individuals by enumeration of Mycobacterium tuberculosis-specific T cells. AIDS 2002; 16: 2285-2293

28 Pathan AA, Wilkinson KA, Klenerman P et al. Direct ex vivo analysis of antigen-specific IFN- $\gamma$-secreting CD4 T cells in Mycobacterium tuberculosis-infected individuals: associations with clinical disease state and effect of treatment. J Immunol 2001; 167: 5217-5225

${ }^{29}$ Ravn P, Munk ME, Andersen ÅB et al. Prospective evaluation of a whole-blood test using mycobacterium tuberculosis-specific antigens ESAT-6 and CFP-10 for diagnosis of active tuberculosis. Clin Diagn Lab Immunol 2005; 12: 491 - 496

${ }^{30}$ Mazurek GH, LoBue PA, Daley CL et al. Comparison of a whole-blood interferon gamma assay with tuberculin skin testing for detecting latent Mycobacterium tuberculosis infection. JAMA 2001; 286: $1740-1747$

${ }^{31}$ Fietta A, Meloni F, Cascina A et al. Comparison of a whole-blood interferon- $\gamma$ assay and tuberculin skin testing in patients with active tuberculosis and individuals at high or low risk of Mycobacterium tuberculosis infection. Am J Infect Control 2003; 31: 347-353

${ }^{32}$ Ewer K, Deeks J, Alvarez L et al. Comparison of T-cell-based assay with tuberculin skin test for diagnosis of Mycobacterium tuberculosis infection in a school tuberculosis outbreak. Lancet 2003; 361: $1168-1173$
${ }^{33}$ Kang YA, Lee HW, Yoon HI et al. Discrepancy between the tuberculin skin test and the whole-blood interferon $\gamma$ assay for the diagnosis of latent tuberculosis infection in an intermediate tuberculosis-burden country. JAMA 2005; 293: 2756-2761

${ }^{34}$ Pai M, Gokhale K, Joshi R et al. Mycobacterium tuberculosis infection in health care workers in Rural India. JAMA 2005; 293: 2746-2755

${ }^{35}$ Lalvani A, Pathan AA, Durkan $H$ et al. Enhanced contact tracing and spatial tracking of Mycobacterium tuberculosis infection by enumeration of antigen-specific T cells. Lancet 2001; 357: 2017-2021

${ }^{36}$ Hill PC, Brookes RH, Fox A et al. Large-scale evaluation of enzymelinked immunospot assay and skin test for diagnosis of Mycobacterium tuberculosis infection against gradient of exposure in The Gambia. CID 2004; 38: 66-973

${ }^{37}$ Richeldi L, Ewer K, Losi M et al. T cell-based tracking of multidrug resistant tuberculosis infection after brief exposure. Am J Respir Crit Care Med 2004; 170: $288-295$

${ }^{38}$ Brock I, Munk ME, Kok-Jensen A et al. Performance of whole blood IFN- $\gamma$ test for tuberculosis diagnosis based on PPD or the specific antigens ESAT-6 and CFP-10. Int J Tuberc Lung Dis 2001; 5: 462 - 467

39 Lalvani A, Nagvenkar P, Udwadia Z et al. Enumeration of T cells specific for RD1-encoded antigens suggests a high prevalence of latent Mycobacterium tuberculosis infection in healthy urban Indians. J Infect Dis 2001; 183: 469-477

${ }^{40}$ Arend SM, Meijgaarden KE van, Boer K de et al. Tuberkulin skin testing and in vitro $\mathrm{T}$ cell responses to ESAT- 6 and culture filtrate protein 10 after infection with Mycobacterium marinum or M. kansasii. J Infect Dis 2002; 186: 1797-1807

${ }^{41}$ Geluk A, Meijgaareden KE van, Franken KL et al. Identification and characterization of the ESAT-6 homologue of Mycobacterium leprae and T-cell cross reactivity with Mycobacterium tuberulosis. Infect Immun 2002; 70: $2544-2548$

${ }^{42}$ Lein $\mathrm{AD}$, Reyn $\mathrm{CF}$ von, Ravn $\mathrm{P}$ et al. Cellular immune responses to ESAT-6 discriminate between patients with pulmonary disease due to Mycobacterium avium complex and those with pulmonary disease due to Mycobacterium tuberculosis. Clin Diagn Lab Immunol 1999; 6: $606-609$

${ }^{43}$ Rolinck-Werninghaus C, Magdorf K, Stark K et al. The potential of recombinant antigens ESAT-6, MPT63 and mig for specific discrimination of Mycobacterium tuberculosis and M. avium infection. Eur J Pediatr 2003; 162: 534-536

${ }^{44}$ Carrara S, Vincenti D, Petrosillo N et al. Use of a T-cell based assay for monitoring efficacy of antituberculosis treatment. Clin Inf Dis 2004; 38: $754-756$

${ }^{45}$ Al-Attiyah R, Mustafa AS, Abal AT et al. Restoration of mycobacteria antigen-induced proliferation and interferon-gamma responses in peripheral blood mononuclear cells of tuberculosis patients upon effective chemotherapy. FEMS Immunol Med Microbiol 2003; 38: 249-256

${ }^{46}$ Ulrichs T, Anding P, Kaufmann SHE et al. Numbers of IFN- $\gamma$-producing cells against ESAT-6 increase in tuberculosis patients during chemotherapy. Int J Tuberc Lung Dis 2000; 4: 1181-1183

47 Vekemans J, Lienhardt C, Sillah JS et al. Tuberculosis contacts but not patients have higher gamma interferon responses to ESAT- 6 than do community controls in The Gambia. Infect Immun 2001; 69: $6554-6557$

${ }^{48}$ Wu-Hsieh BA, Chen CK, Chang JH et al. Long-lived immune response to early secretory antigenic target 6 in individuals who had recovered from tuberculosis. Clin Infect Dis 2001; 33: 1336-1340

${ }^{49}$ Stuart RL, Olden D, Johnson PDR et al. Effect of anti-tuberculosis treatment on the tuberculin interferon- $\gamma$ response in tuberculin skin test (TST) positive health care workers and patients with tuberculosis. Int J Tuberc Lung Dis 2000; 4: 555-561

50 Nicol MP, Pienaar D, Wood K et al. Enzyme-linked immunospot assay responses to early secretory antigenic Target 6, Culture Filtrate Protein 10, and Purified Protein Derivative among children with tuberculosis: implications for diagnosis and monitoring of therapy. CID 2005; 40: $1301-1308$

51 Dheda K, Chang JS, Kim LU et al. Interferon gamma assays for tuberculosis. Lancet Infect Dis 2005; 5: 324-325

52 Doherty TM, Demissie A, Menzies D et al. Effect of sample handling on analysis of cytokine responses to Mycobacterium tuberculosis in clinical samples using ELISA, ELISPOT and quantitative PCR. J Immunol Methods 2005; 298: 129-141

53 Arend SM, Engelhard AC, Groot G et al. Tuberkulin skin testing compared with T-cell responses to Mycobacterium tuberculosis-specific and 
non-specific antigens for detection of latent infection in persons with recent tuberculosis contact. Clin Diagn Lab Immunol 2001; 8: $1089-1096$

${ }^{54}$ Bellete B, Coberly J, Barnes GL et al. Evaluation of a whole-blood interferon-gamma release assay for the detection of Mycobacterium tuberculosis infection in 2 study populations. Clin Inf Dis 2002; 34: 1449- 1456

${ }^{55}$ Mazurek GH, LoBue PA, Daley CL et al. Detection of Mycobacterium tuberculosis infection by whole-blood interferon-gamma assay. Clin Infect Dis 2003; 36: 1207-1208

${ }^{56}$ Rothel JS, Radford AJ. Comparison of tuberculosis tests: finding truth or confirming the prejudice? Clin Inf Dis 2003; 36: 1206-1207

57 Schölvinck E, Wilkinson KA, Whelan AO et al. Gamma interferonbased immunodiagnosis of tuberculosis: comparison between wholeblood and enzyme-linked immunospot methods. J Clin Microbiol 2004; 42: 829-831

${ }^{58}$ Doherty TM, Demissie A, Olobo J et al. Immune responses to the Mycobacterium tuberculosis-specific antigen ESAT-6 signal subclinical infection among contacts of tuberculosis patients. J Clin Microbiol 2002; 40: 704-706

${ }^{59}$ Barnes PF. Diagnosing latent tuberculosis infection. Turning glitter to gold. Am J Respir Crit Care Med 2004; 170: 5-6

60 Pittius NCG Van, Gamieldien J, Hide W et al. The ESAT-6 gene cluster of Mycobacterium tuberculosis and other high G+C Gram-positive bacteria. Genome Biol 2001; 2: research 004.1-0044.18

${ }^{61}$ Harboe M, Oettinger T, Wiker HG et al. Evidence for occurrence of the ESAT-6 protein in Mycobacterium tuberculosis and virulent Mycobacterium bovis and for its absence in Mycobacterium bovis BCG. Infect Immun 1996; 64: 16-22

${ }^{62}$ Martin-Casabona N, Bahrmand AR, Bennedsen J et al. Non-tuberculous mycobacteria: patterns of isolation. A multi-country retrospective study. Int J Tuberc Lund Dis 2004; 8: 1186-1193

${ }^{63}$ Richeldi L, Ewer K, Losi M et al. Early diagnosis of subclinical multidrug-resistant tuberculosis. Ann Intern Med 2004; 140: 709- 713

${ }^{64}$ Elliott AM, Hurst TJ, Balyeku MN et al. The immune response to Mycobacterium tuberculosis in HIV-infected and uninfected adults in Uganda: application of a whole blood cytokine assay in an epidemiological study. Int J Tuberc Lung Dis 1999; 3: 239-247

${ }^{65}$ Liebeschuetz S, Bamber S, Ewer K et al. Diagnosis of tuberculosis in South African children with a T-cell-based assay: a prospective cohort study. Lancet 2004; 364: 2196-2203

\section{Preisausschreibung}

\section{Franz-Redeker-Preis}

Das Deutsche Zentralkomitee zur Bekämpfung der Tuberkulose mit Unterstützung durch die Deutsche Gesellschaft für Pneumologie schreibt hiermit den Franz Redeker-Preis aus. Mit dem Preis in Höhe von EUR 5.000 soll die beste Arbeit auf dem Gebiet der Tuberkulosebekämpfung unter sozial-medizinischen Aspekten ausgezeichnet werden. Die Bewerbung steht allen auf dem Gebiet arbeitenden Ärzten offen. Das Manuskript kann in deutscher, englischer, französischer oder spanischer Sprache verfasst sein; ein Abstract in englischer Sprache ist beizufügen. Manuskript und Abstract müssen bis zum 15. Mai 2006 in vierfacher Ausfertigung an folgende Anschrift gesandt werden:

Prof. Dr. Robert Loddenkemper, Generalsekretär des Deutschen Zentralkomitees zur Bekämpfung der Tuberkulose, Lungenklinik Heckeshorn, Zum Heckeshorn 33, 14109 Berlin, Tel.: 030/ 80022435, Fax: 030/80022286, E-mail: loddheck@ zedat.fu-berlin.de

Der Preis soll anlässlich des 37. Weltkongresses der Internationalen Union gegen Tuberkulose und Lungenkrankheiten (IUATLD) vom 31. Oktober bis 4. November 2006 in Paris verliehen werden. 